\title{
Der Psalmencommentar des Theodor von Mopsuestia in syrischer Bearbeitung.
}

\author{
Von Friedrich Baethgen.
}

In meinen Händen befindet sich eine mir vom Besitzer, Herrn Professor Sachau in Berlin, freundlichst zur Verfügung gestellte syrische Handschrift ${ }^{1}$ ), welche folgendermafsen anfängt :

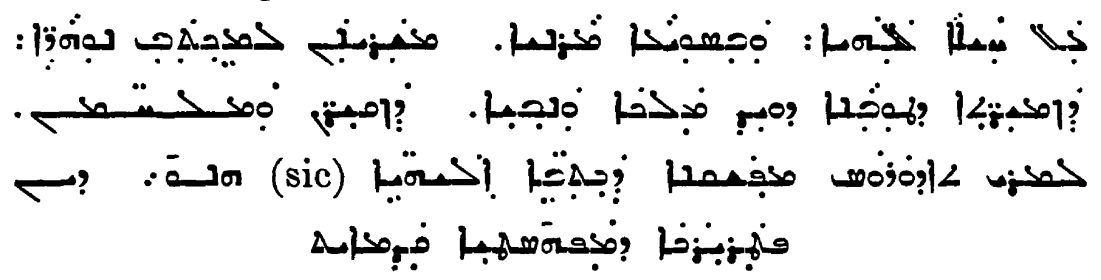

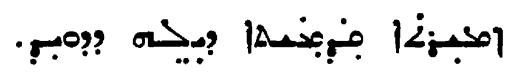

D. i. „Mit Hülfe Gottes und unter dem Beistande des Herrn beginnen wir zu schreiben die Erläuterungen der Psalmen des Königs und Propheten David, welche verfalst und hergestellt sind von Mâr Theodoros, dem Ausleger der göttlichen Schriften, d. h. dem Patriarchen von Mopsuestia.

\section{Zuerst}

Psalm I, von David.“

Ich gebe zuerst eine Beschreibung der Handschrift. Höhe $31 \mathrm{~cm}$, Breite $23 \mathrm{~cm}, 19$ Lagen (صفزعا) zu je 10 Blättern, aufser der ersten und sechsten Lage, welche nur 8 Blätter haben, ohne dafs im Text etwas fehlte. Im Ganzen also 186 Blätter. Eine Paginirung ist nicht vorhanden; dagegen sind die einzelnen Lagen auf der ersten und letzten Seite vom.Schreiber durch Buchstaben beziffert. Die ersten sieben und die letzte Seite sind unbeschrieben. Geschrieben auf europäischem Papier mit dem Wasserzeichen F. F. PALAZZUOLI in schöner grofser und deutlicher nestorianischer Schrift, die durchgehend mit Vocalpunkten nebst Rukkâkhâ und Qưšâyâa versehen

') Jetzt in den Besitz der Kgl. Bibliothek zu Berlin übergegangen! 
ist $^{1}$ ). Durch Einflufs von Feuchtigkeit ist das Papier vielfach dunkelgrau geworden und sind die Schriftzüge hin und wieder auf den gegenüberstehenden Seiten abgekleckst. Die Rubra der Inhaltsangaben zu den einzelnen Psalmen sind zum Theil verwischt, doch sind kaum einige wenige Worte ganz unleserlich geworden.

Nach dem Colophon auf den beiden vorletzten Seiten ist die Abschrift beendet am 29. Teschrin II 1882 p. Chr. zu Telkêphê, einer in der Nähe von Mosul am Tigris belegenen Ortschaft ${ }^{2}$ ). Als Schreiber nennt sich der Diakon = Eranciscus

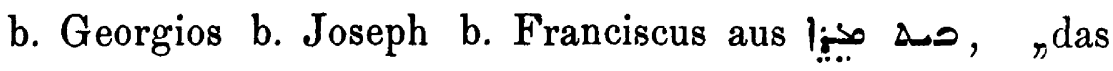
zu Telkêphê gehört". Trotz mancher Fehler ist die Handschrift doch besser als man bei solch geringem Alter erwarten möchte; der Schreiber hat jedenfalls recht gute Kenntnisse des Altsyrischen.

Von Vulgarismen ist mir nur $\psi 83,17$ statt $i_{\gamma_{3}}^{3}$ ) aufgestolsen. Fast regelmälsig wird oه u. dgl. für or of geschrieben.

Die Handschrift enthält auf den ersten 179 Blättern einen Commentar übr die Psalmen, der nach der Ueberschrift von Theodor von Mopsuestia verfalst ist. Nach

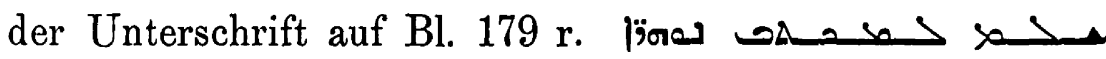

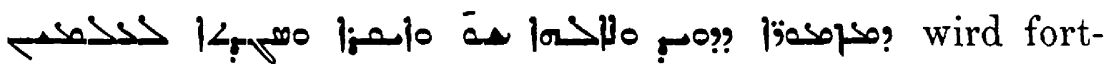

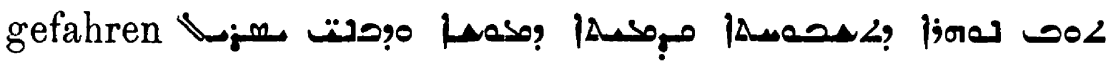
„W „Ferner Erläuterung des ersten Lobgesanges Mosis und der Kinder Israel für ihre Errettung “ (Exod. 15, 1-21). Bl. 181 r. folgt ein gleicher Commentar über das Loblied des Propheten Jesaias (Jes. 42, 10-13.

1) In den unten abgedruckten Stücken sind diese Punkte wegen der typographischen Schwierigkeiten grölstentheils fortgelassen.

- $\left.\quad{ }^{2}\right)$ S. Rosen und Forshall, Catalog. Cod. orient. Mus. Brit. pp. 4. 5. 7.

s) Vgl. Nöldeke, Gram. d. neusyr. Sprache § 22. 
$45,8) ; 181 v$. ein ebensolcher über den zweiten Lobgesang Mosis (Deut. 32, 1-21 a); endlich 183r. unter dem Rubrum

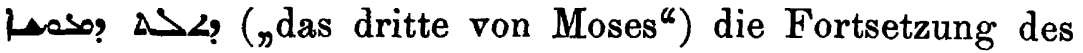
Vorhergehenden, beginnend mit den Worten (J) (Deutern. 32, $21 \mathrm{~b}-43$ ). Es wird in der Handschrift nicht gesagt, dafs die Erläuterungen zu diesen letzteren Abschnitten von Theodor herstammten, sie sind aber ganz in demselben Stil gehalten, wie die zu den Psalmen. Sind nun diese Erläuterungen wirklich die syrische Uebersetzung des von Theodor griechisch geschriebenen, bis auf einige Fragmente verloren gegangenen Psalmencommentars?

Dals Theodor einen Commentar zu den Psalmen geschrieben hat, sagt er selbst ${ }^{1}$ ), und zwar war dies Werk, ebenfalls nach seiner eignen Aussage, seine erste literarische Leistung ${ }^{2}$ ), die er, kaum $20 \mathrm{Jahre}$ alt $^{3}$ ), niederschrieb.

Nach dem Katalog kirchlicher Bücher, welchen der 1318 verstorbene nestorianische Schriftsteller Ebedjesu, Metropolit von Șoba (Nisibis) verfafst hat, wurden die Schriften Theodors durch den bekannten Ibas von Edessa $(\dagger 457)$ in das Syrische übersetzt, wobei ihm zwei Lehrer an der Schule zu Edessa, Cumas und Probus, zur Seite standen ${ }^{4}$ ). Nach Bar Hebraeus soll auch der Perser Maanes, welcher zur Zeit des Rabulas die Schule von

1) Vgl. Comment. in Hoseam proph. Prooem. Zach. 9, 9. al.

2) Quae scripta sunt in.psalmos .. . quae etiam prima ceterorum omnium scripsimus bei Facundus von Hermiane pro defens. trium capp. III, 6.

3) Hunc aiunt non amplius quam decem et octo annos natum in scripturas debacchatum esse. Leontius von Byzanz, angeführt bei Fritzsche, De Theodori Mopst. vita et scriptis p. 27, und dazu die Bemerkung von Tillemont ebeuda.

4) Assem. Bibl. or. III. I. 85. 
Edessa besuchte, während seines dortigen Aufenthalts die Schriften Theodors in das Syrische übersetzt haben ${ }^{1}$ ).

Sie standen bei den syrischen Nestorianern im höchsten Ansehen; durch Concilbeschlüsse wurde die bindende Auctorität Theodors für die Schriftauslegung wiederholt officiell festgesetzt; wer ihn bekämpfte wurde mit dem Anathem belegt ${ }^{2}$ ), und er führt noch heute bei den syrischen Nestorianern den Ehrennamen des Exegeten $x a \tau$ ' $\varepsilon \xi \circ \eta^{\prime} j$.

Dafs unter den in das Syrische übersetzten Schriften Theodors ${ }^{3}$ ) sich auch sein Psalmencommentar befand, ist ausdrücklich bezeugt ${ }^{4}$ ); derselbe scheint sogar im 14. Jahrh. dem oben genannten Ebedjesu noch vorgelegen zu haben. Ich glaubte daher, als ich die oben beschriebene Handschrift zum ersten Mal sah, den ächten Commentar Theodors vor mir zu haben. Dem war nun leider nicht so.

Die syrische Handschrift kann schon deswegen keine einfache Uebersetzung von Theodor's Commentar enthalten, weil letzterer seiner Erklärung die Septuaginta zu Grunde legte, während der Psalmentext des syrischen Commentars derjenige der Peschita ist ${ }^{5}$ ). Dem entsprechend ist auch die Zählung der Psalmen in unserem Commentar die der Peschita, d. h. $\psi 9$ und 10 sind getrennt (in LXX zu einem verbunden), 114 und 115 bilden einen einzigen und

1) Assem. Bibl. or. III. I. 378.

2) 1. l. pp. 84. 236. 342. 448.452.

3) Die im Syrischen erhaltenen Fragmente sind gesammelt von E. Sachau, Theodori Mops. fragmenta syriaca, Lipsiae 1869.

4) B. O. III. I. 31.

5) Allerdings sind die Berührungen dieses Textes mit den LXX etwas zablreicher als der von Lee. $\psi 1,4$ findet sich nach f.o; der

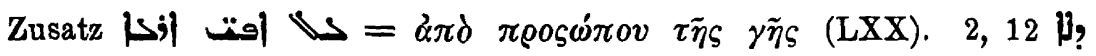

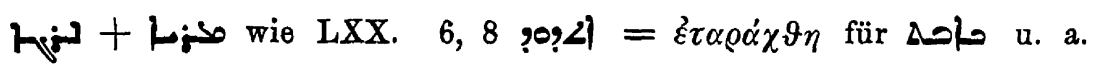
Im Grofsen und Ganzen aber überschreiten die aus LXX eingedrungenen Lesarten doch kaum das Mafs, welches sich auch sonst in manchen syrischen Bibelhandschriften findet. 
147 ist in zwei vertheilt ${ }^{1}$ ). Nun könnte man freilich annehmen, der Syrer hätte den Commentar Theodors übersetzt, dabei aber aus praktischen Gründen den Bibeltext seiner Kirche zu Grunde gelegt. Diese Annahme wird jedoch durch die Beobachtung hinfällig, dafs die Septuaginta und Peschita unter sich (und vom Hebräer) so sehr abweichen, dafs ein Commentar zu der griechischen Uebersetzung vielfach für die syrische gar nicht palst und umgekehrt. Allerdings hat der syrische Uebersetzer der Psalmen bei seiner Arbeit die LXX vielfach zu Rathe gezogen ${ }^{2}$ ), trotzdem bleibt eine aufserordentlich grofse Anzahl von Stellen übrig, die in der Peschita ganz abweichend von den LXX übersetzt sind und auf die daher die Erläuterungen des griechischen Textes nicht anwendbar sind, vgl. z. B. in beiden Uebersetzungen die Stellen 2, 6. 12; 4,$3 ; 12,6.9$ u. v. a.

Weiter wäre es mőglich, dafs der syrische Uebersetzer diejenigen Stellen in Theodor's Commentar ausgelassen hätte, welche auf den von ihm zu Grunde gelegten Peschitatext nicht palsten, so dals also bei unserem Syrer allerdings nicht der ganze Theodor erhalten wäre, das aber, was der syrische Commentar bietet, wirklich auf Theodor zurückginge. Aber auch das ist nicht der Fall. Es finden sich nämlich in unserem Commentar eine Anzahl von Stellen, die nur auf den syrischen Text passen, also griechisch nicht existirt haben können, sondern original syrisch sind. Hierher gehören zuerst Erklärungen syrischer Wörter, die zur Zeit der Abfassung des Commentars nicht mehr verstanden wurden.

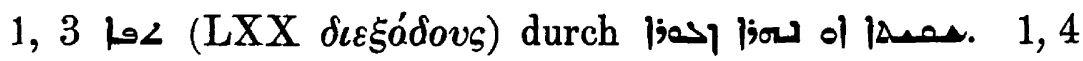

1) Vgl. meine „Untersuchungen über die Psalmen nach der Peschita ${ }^{4}$ p. 9. - Ich citire auch in der vorliegenden Abhandlung überall nach dem hebräischen Text.

2) Vgl. meine Abhandlung : „Der textkritische Werth der alten Uebersetzungen zu den Psalmen ${ }^{*}$ in Jahrb. f. prot. Theol. 1882 S. 435 ff. 


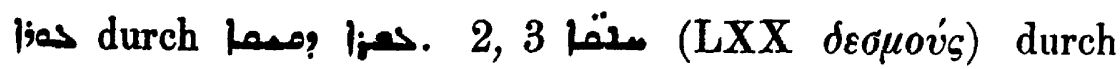

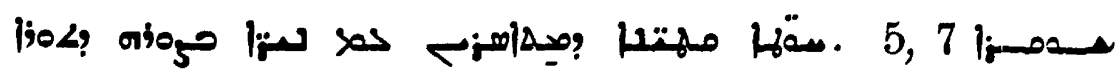

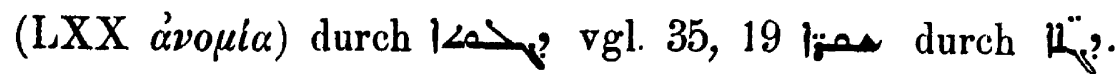

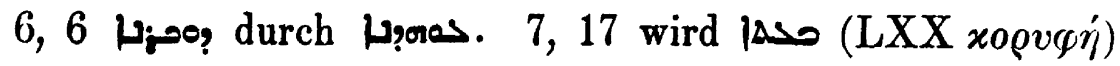
durch den Zueatz

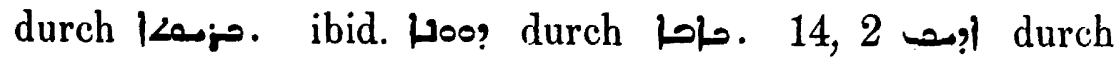

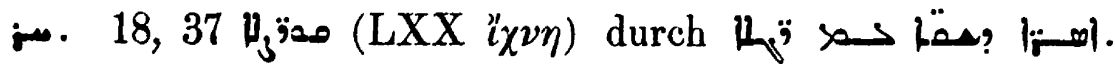

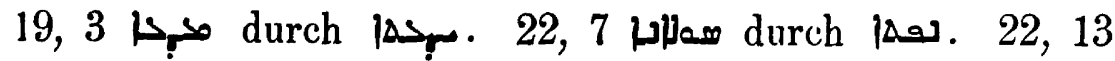

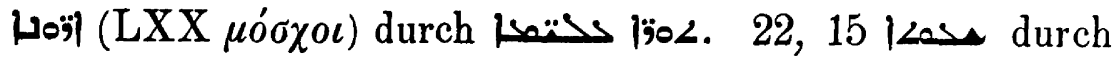

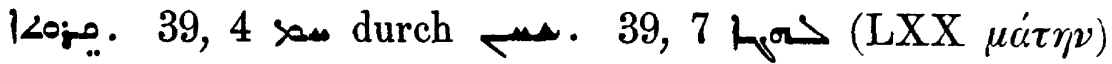
durch 68,14

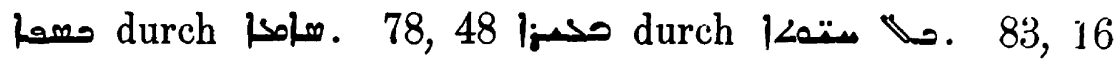

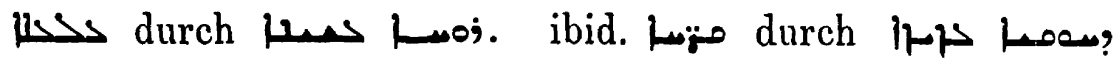

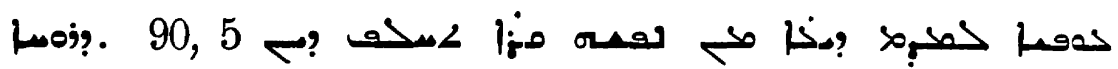
91,6

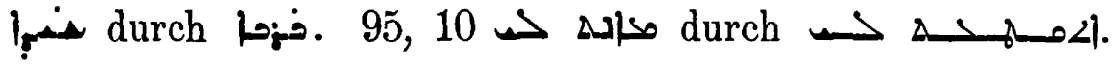

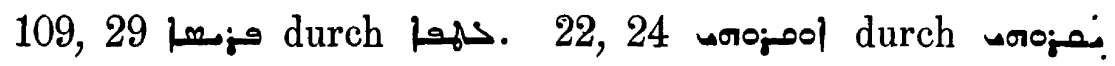
u. v. a.

Auf'ser diesen originalsyrischen Worterklärungen finden sich nun aber im Commentar auch weitere Ausführungen und Erläuterungen, die nur auf den Peschitatext passen, nicht aber auf den Text der LXX. 12, 9 liest unser Commentar mit Pesch. לכיוּן des Hebräers). Dies wird folgendermafsen erläutert : إ

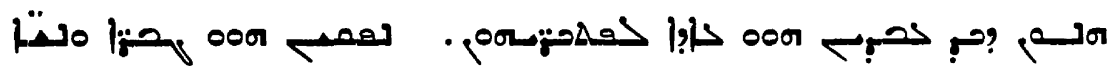
خز

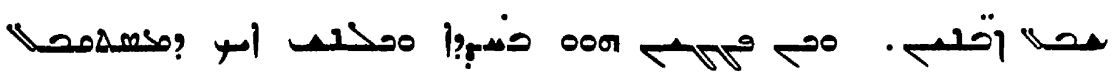
. Lor oor o. Edom d. i. Esau. Wenn diese ihren 
Götzen ein Fest feierten, so gingen Männer und Weiber nackt hinaus und gingen nach dem Gesetz des Heidenthums sieben Mal um jenen hohen Hügel herum; so trieben sie Kurzweil mit einander jeder wie es sich traf. So thaten sie."

Da die LXX dem Hebräer entsprechend übersetzen

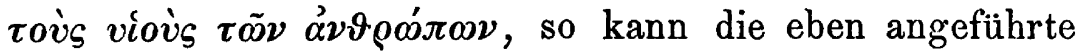
Erläuterung nicht aus einem griechischen Original herübergenommen sein, sondern mufs originalsyrisch sein. Dasselbe gilt von den folgenden Stellen. 21, 13a übersetzt

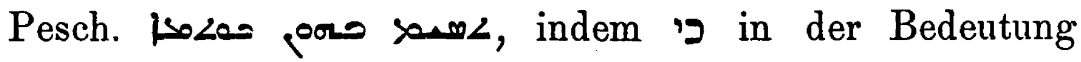
stigma genommen wurde ${ }^{1}$ ). Dies bا Lo erläutert unser

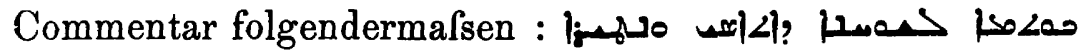

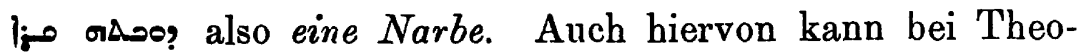
dor nichts gestanden haben, da LXX lesen ö $\tau \iota \vartheta \dot{\eta} \sigma \varepsilon \iota \varsigma$

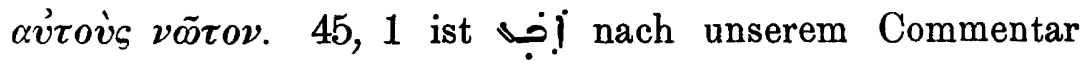
Imperativ, LXX dagegen $\varepsilon^{\prime} \xi \eta \varrho \varepsilon v \dot{\xi} \alpha \tau o$ u. v. a.

Die letzte Hoffnung, die Autorschaft Theodor's für unsern Commentar retten zu können, wird vernichtet durch eine Vergleichung der erhaltenen griechischen Fragmente mit unserm Syrer.

Zu $\psi$ 1, 1 führt Theodor aus ${ }^{2}$ ), das Prädikat „selig“ eigne eigentlich nur Gott; er mache uns aber desselben theilhaftig, und zwar sei dies Prädikat eine Frucht der Vollkommenheit in der Tugend. Von dieser Auseinandersetzung findet sich im syrischen Commentar nichts, obgleich sie ebenso gut auf das syrische sod pafst wie auf raxáoıos. Der Syrer hat statt dessen nur das Scholion

1) S. meine Abhandlung „Der textkr. Werth u. s. w. ${ }^{4}$ p. 612.

2) Bei Corderius, Expositio patrum graecorum in psalmos. Antverpiae 1643, Tom. I p. 8. Die Sammlung der Fragmente bei Migne, Patrologiae cursus compl. tom. 66 habe ich leider bei der Ausarbeitung dieses Aufsatzes nicht benutzen können. 
صAزم (, in beiden Welten"), wovon in dem griechischen Fragment Nichts steht ${ }^{1}$ ). Ebensowenig finden sich in dem syrischen Commentar die griechisch erhaltenen Fragmente zu 2, 7 (Cord. I 32); 16, 8 (Cord. I 276); 18, 8 (Cord. I 328); 18, 11 (Cord. I 330); 53, 7 (Cord. II 27); 54, 1 (Cord. II 35) u. a. Aufserdem steht fest, dafs Theodor in seinen früheren exegetischen Schriften auch die übrigen griechischen Uebersetzer für die Erklärung heranzog $\left.{ }^{2}\right)$; im Psalmencommentar citirt er Symmachus z. B. 56, 3 (Cord. II 94); 61, 3 (Cord. II 20)); 73, 13 (Cord. II 503); Aquila, Theodotion und Symmachus zu 1, 5 (Cord. I, 16) und sonst. Leider werden diese Uebersetzer in dem syrischen Commentar nirgends erwähnt. Ebenso fehlt endlich die Vorrede an Cerdo, dem Theodor nach dem Zeugnisse des Ebedjesn sein Buch gewidmet hat.

Wenn also auf Grund der vorstehenden Untersuchungen die Hoffnung aufgegeben werden mufs, das Werk wiedergefunden zu haben, welches zum ersten Mal die grammatisch-historische Auslegung principiell zur Anwendung gebracht hat, so enthält unser syrischer Commentar doch Vieles, was auffallend an Theodor erinnert und direct auf ihn zurückzuführen ist.

Die formale Anlage von Theodor's Commentar charakterisirt Fritzsche ${ }^{3}$ ) nach den erhaltenen Fragmenten folgendermalsen : fere scriptoris sententiam aliis verbis repetiit. Das ist ungefähr auch die Methode des syrischen Commentars; er umschreibt den Psalmentext, indem er zwischen die einzelnen Worte erläuternde Anmerkungen und Glossen

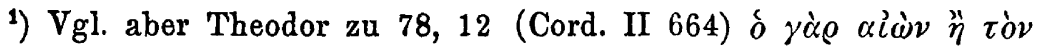

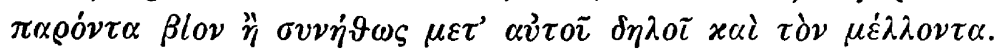

$\left.{ }^{2}\right)$ S. Kihn, Theodor von Mopsuestia nnd Junilius Africanus als Exegeten 1880 pp. 90. 92.

3) 1 l. p. 35 vgl. 57 solet . . . plerumque ipsa prophetae verba ex $L X X$ interpretatione afferre eaque explicare. 
einschiebt, die allerdings aufserordentlich dürr und dürftig sind. Als Beispiel lasse ich die Erklärung von $\psi 6$ genau nach dem Manuscript hier abdrucken :

"גA.

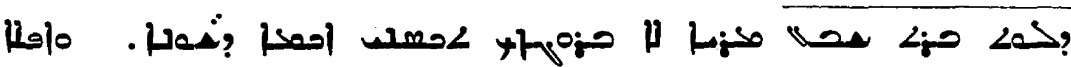

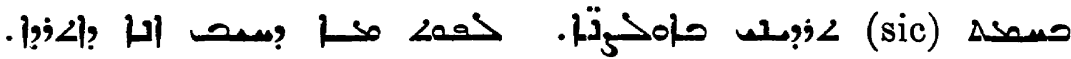

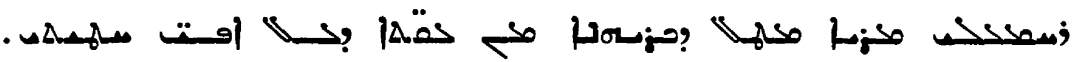

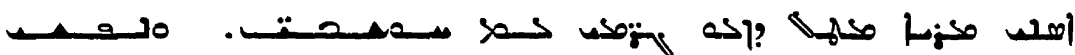

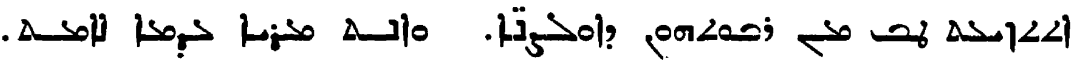

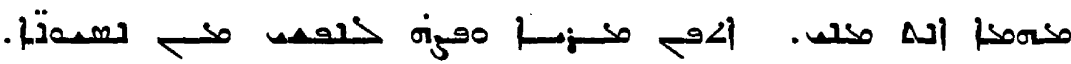

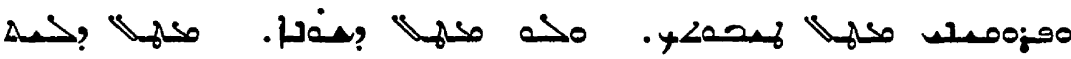

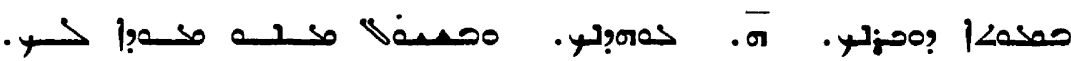

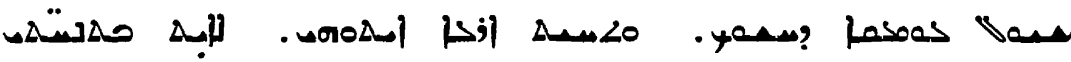

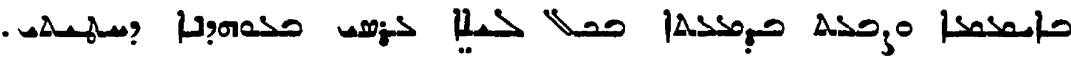

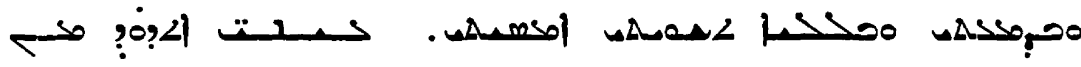

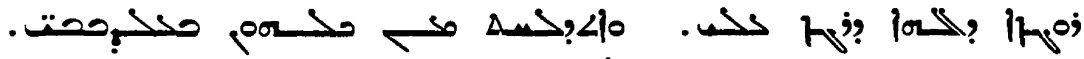

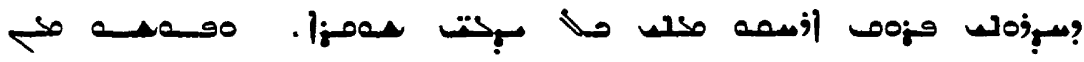

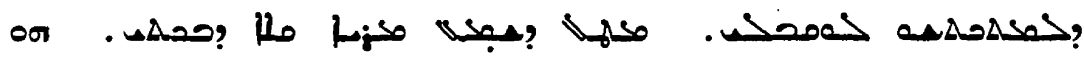

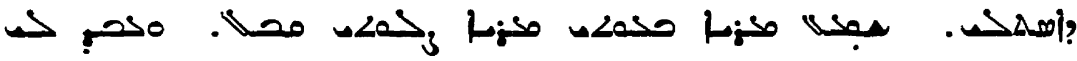

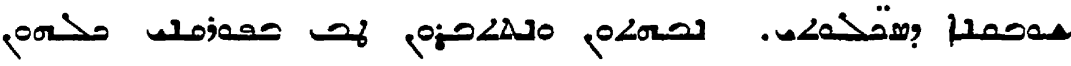

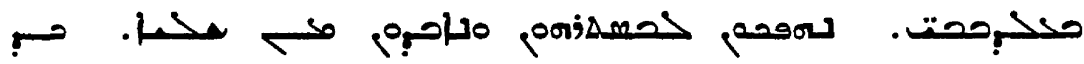

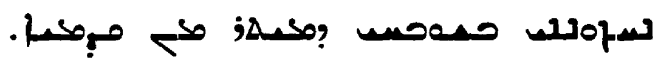

„VI. Gebet Davids als er in Nöthen war wegen seiner Vergehung gegen Batseba. 2. Herr strafe mich nicht in deinem Zorn, wie ich verdiene; und züchtige mich nicht mit Bedrängnissen in deinem Grimm, wie ich schuldig bin gezüchtigt zu werden. 3 Sei mir gnädig Herr, denn ich bin krank von den Bedrängnissen wegen meiner Sünde. Heile mich Herr, denn erschrocken sind meine Gebeine 
sammt meinen Gedanken. 4 Und meine Seele ist sehr erschrocken durch die Gröfse der Bedrängnisse; und $d u$ Herr wie so lange vernachlässigst du mich. 5 Wende dich Herr und errette meine Seele von Versuchungen und rette mich wegen deiner Güte und nicht wegen meines Verdienstes. 6 Denn im Tode ist keine Erinnerung an dich d. h. Gedenken an dich, und in der Hölle - wer dankt dir? Die Hölle ist eine finstere Tiefe unter der Erde. 7 Ich bin müde von meinem Seufzen bei Tage und schwemme mit Thränen jede Nacht mein Lager in Gedanken an meine Sünde und mit meiner Thräne und bei Nacht netze ich mein Bette. 9 Meine Augen sind aufgeregt vom Zorne Gottes, der auf mich zürnt, und ich bin in Schrecken versetzt durch alle meine Feinde, die mich umgeben. 9 Weichet, entfernt euch, von mir alle Uebelthäter [lies sä] und höret auf, gegen mich zu kämpfen, denn der Herr hat mein lautes Weinen gehört, das verworfen war; 10 gehört hat der Herr meine Bitte, der Herr hat mein Gebet angenommen und hat mir Vergebung für meine Uebertretungen gewährt. 11 Es werden zu Schanden und gebrochen werden gar sehr wegen meiner Rettung alle meine Feinde; sie werden sich rückwärts wenden und plötzlich zu Grunde gehen, wenn sie mich in meiner Herrlichkeit sehen, die gröfser ist als die frühere."

In derselben dürren und dürftigen Weise wie diese Metaphrase ist der ganze Commentar abgefalst; längere Auseinandersetzungen finden sich nur ganz vereinzelt ${ }^{1}$ ).

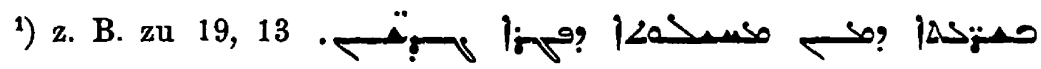

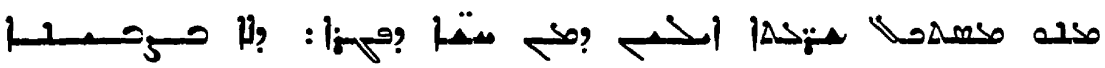
of

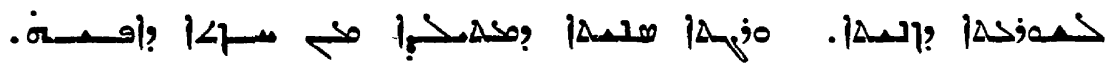

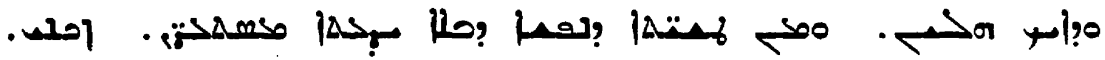


Allerdings hat Theodor selbst sich ziemlich abfällig über sein Erstlingswerk geäu(sert ${ }^{1}$ ), aber die syrische Nachahmung kann auch niedrig gespannte Erwartungen nicht befriedigen. Trotzdem ist dies syrische Buch insofern von Interesse und Wichtigkeit, als es eine grolse Anzahl materieller Berührungen mit Theodor enthält oder vielmehr gewissermafsen seinen Psalmencommentar in nuce darbietet. Der Beweis für diese Behauptung ist nunmehr zu führen.

Zunächst finden sich bei unserm Syrer Sätze, die, wie sich aus den griechischen Fragmenten erweisen läfst, direct aus dem Commentar Theodors entnommen sind. Allerdings sind alle diese Stellen bei dem Syrer in aufserordentlich starker Verkürzung wiedergegeben, so dafs sein

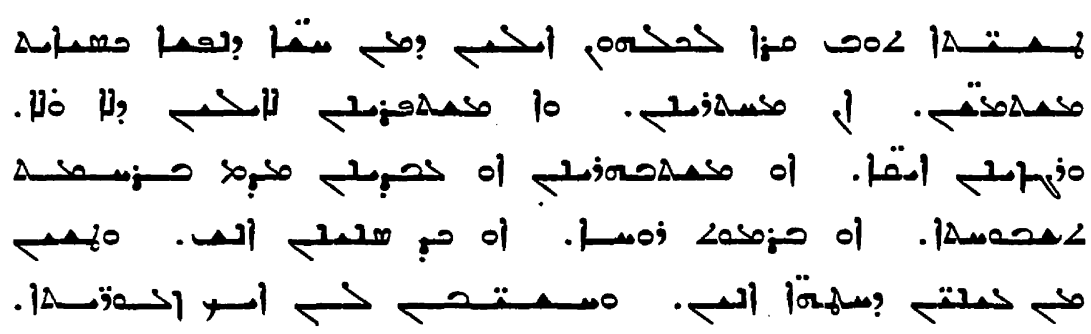
${ }_{n}$ Wer erkennt die Uebertretungen (LXX $\left.\pi \alpha \rho \alpha \pi \tau \omega \mu \alpha \tau \alpha\right)$, die aus der Schwäche des Leibes entstehen. Debertretungen sind das, was nicht absichtlich aus den Leidenschaften $\left(\pi \alpha^{\prime} \vartheta \eta\right)$ des Leibes kommt, wie wenn wir etwa betrunken sind oder unmäfsig essen oder Lust haben an Fabeleien, oder an der Sünde der Hurerei oder an der bösen Lust, welche aus ibrem Anschauen(?) geboren wird u. dgl. Ond von den verborgenen Sünden der Seele, welche ohne Wissen vollbracht werden, reinige mich. Verborgene Sünden nennt er alles das, was im Verborgenen von den Leidenschaften der Seele verübt wird, wie wenn wir stolz sind oder denen zu gefallen suchen, welchen es nicht zukommt oder ohne Grund zürnen oder hoffärtig sind oder etwas aus Ehrgeiz thun oder aus Hochmuth oder wenn wir jemanden hassen. Bei derlei ist vor unsern Augen verborgen, dafs es Sünden sind und es dünkt uns geringfügig za sein."

1) Bei Facundus von Hermiane pro defens. trium capp. III 6, angeführt bei Fritzsche p. 36. 
Commentar vielmehr als eine Scholiensammlung aus Theodor zu bezeichnen ist. Ich führe eine Anzahl solcher Stellen an.

Zu 1, 5 a مكه or bietet der

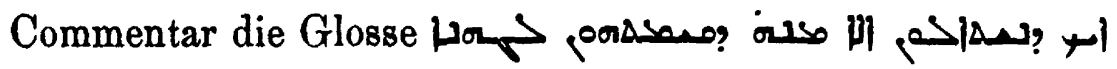
مuدوزتم. Dies ist die ziemlich genaue Wiedergabe der

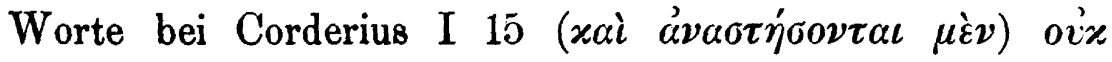

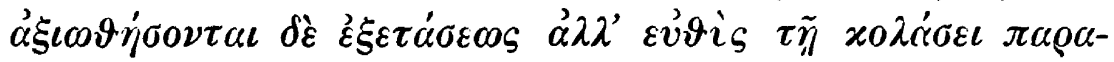

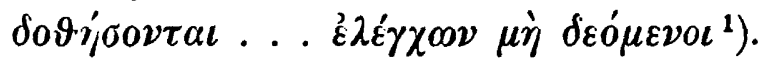

19, 13 sagt der Commentar (lies Vgl. dazu Cord. I 575

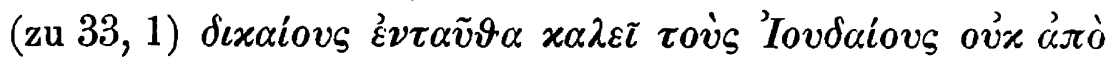

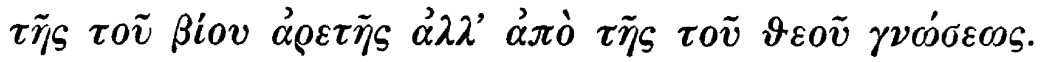

33, 1 Cord. I 575

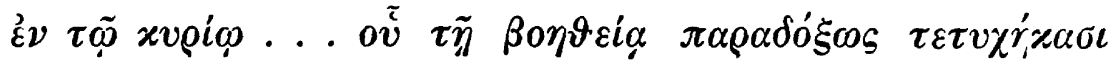

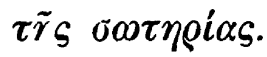

55 ist nach dem syrischen Commentar dem Hohenpriester Onias in den Mund gelegt (s. u.); v. 14 ist der

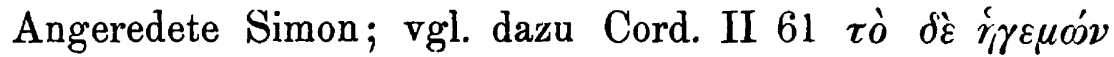

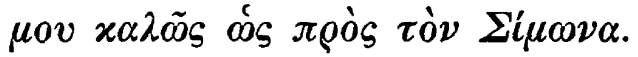

58,4 „Die Lügner irren vom Mutterleibe an“; dazu

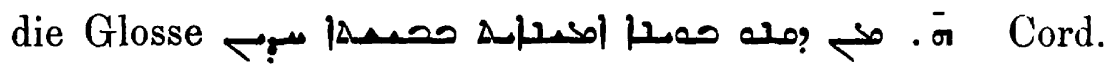

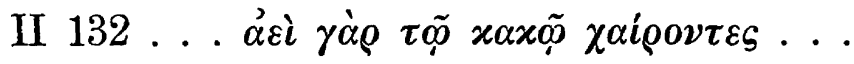

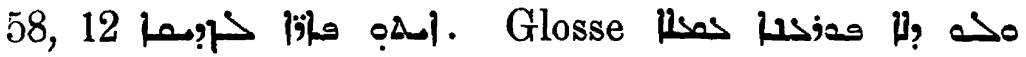

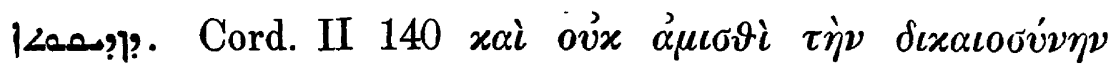

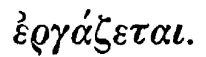

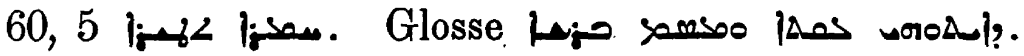

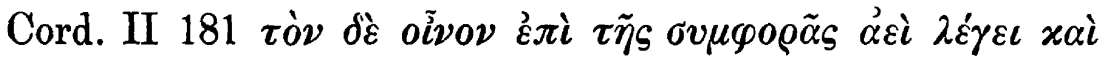
$\tau \tilde{\eta} s \tau \mu \omega \rho i \alpha s$.

1) Bei Corderius wird diese Ausführung Theodoret zugeschrieben; Fritzsche 1. l. p. 28 unten hat richtig vermuthet, dals sie Theodor angehört. 


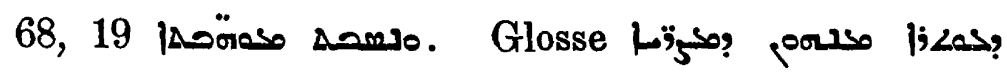
> كمدتدا , Vgl. Cord. II 357, wo Theodor ausführt, dieser Vers gehe auf die Befreiung der Israeliten

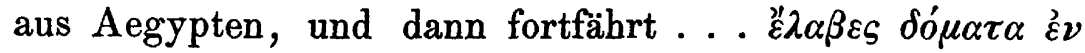

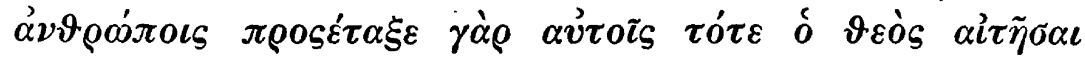

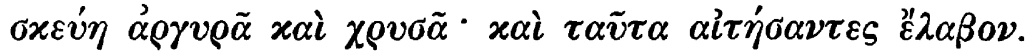

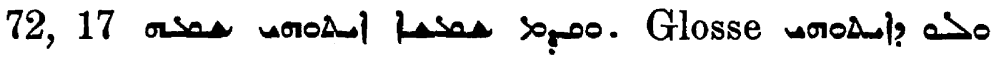

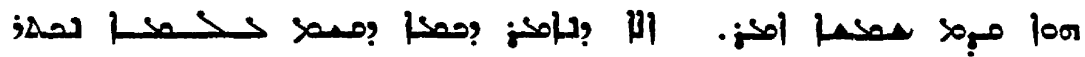

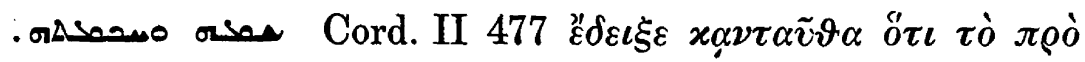

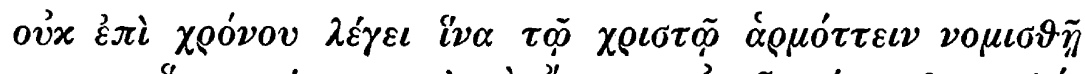

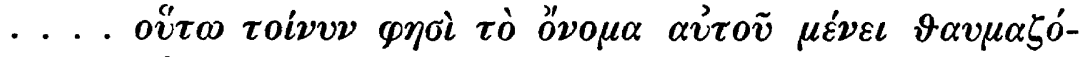

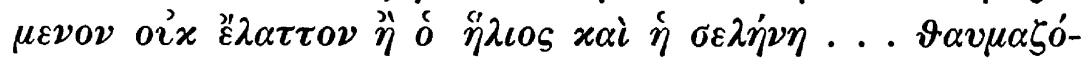

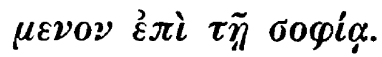

75, 2 Glosse كمن . Cord. II 551 xai

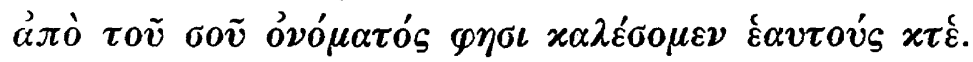

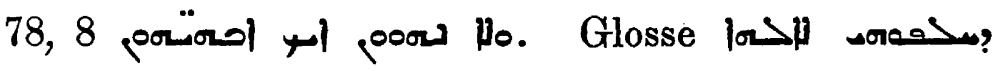

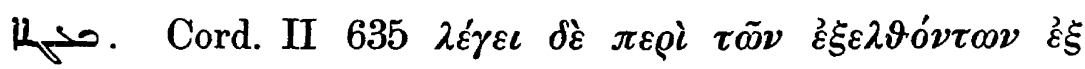
$\alpha i \gamma v \dot{\pi} \tau o v \quad x \tau \varepsilon$.

Man sieht aus diesen Beispielen, verglichen mit den bei Corderius in extenso gegebenen Fragmenten, wie der Verfasser des syrischen Commentars sich in der Regel nur die Stichworte aus Theodor zu eigen macht, oder wie er sich bisweilen (vgl. die letzten Beispiele) auch damit begnügt, den allgemeinen Sinn seines Gewährsmannes auszudrücken. Dieselbe Verkürzung im Verhältnifs zum griechischen Theodor zeigt sich nun auch bei den syrischen Ueberschriften oder Inhaltsangaben, welche in mehrfacher Beziehung den interessantesten Theil unseres Commentars ausmachen. Die bis jetzt angeführten Beispiele von Berührungen zwischen Theodor und unserem Syrer beweisen nämlich nur, dafs einzelne Bestandtheile aus dem Commentar des letzteren auf Theodor zurückgehen. Dabei wäre

Zeitschrift f. d. alttest. Wiss. Jabrgang 5. 1885. 
es aber immerhin möglich, dafs eben so viel und mehr Erläuterungen aus anderen Quellen geschöpft wären. So könnte der Syrer z. B. eine griechische oder syrische Catene zur Hand gehabt und bald diesen, bald jenen Vater benutzt haben. Dafs dies nicht der Fall ist, sondern dals der Syrer sich mit wenigen Ausnahmen überall an Theodor gehalten und ihn excerpirt hat, beweisen die Ueberschriften, welche er den einzelnen Psalmen giebt. Soweit dieselben nämlich aus den griechischen Fragmenten controllirt werden können, stimmen sie ausnahmslos, wenn

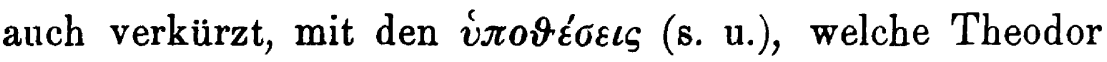
seinen Erklärungen vorausschickte, und mit den entsprechenden Auslegungen des Textes überein. Wenn sich aber diese Uebereinstimmung bei allen erhaltenen Fragmenten constatiren lälst, so darf man schliefsen, dafs wir Theodors Ansichten auch da von dem Syrer wiedergegeben finden, wo die Controlle nicht mehr möglich ist. Im Einzelnen ist hier Folgendes zu bemerken.

Nach Leontius von Byzanz und Theodoret hat Theodor die Ueberschriften, welche die Psalmen bei den LXX führen, für unecht erklärt und beseitigt ${ }^{1}$ ). Auch in dem syrischen Commentar findet sich nun keine Spur von den Ueberschriften, welche die Psalmen im hebräischen oder griechischen Kanon haben, was zweifelsohne auf Theodors Einflufs zurückzuführen ist. Dieser Einflufs hat in der syrischen Kirche sogar so tief gewirkt, dafs auch die Bibelhandschriften, selbst die der Monophysiten, die Ueberschriften des hebräischen Textes nicht enthalten, dafür aber andere, die unter sich sehr verschieden sind ${ }^{2}$ ).

1) S. Kihn, Theodor von Mopsuestia etc. p. 62. 70. Fritzsche, De Theodori Mops. vita et scriptis p. 32.

$\left.{ }^{2}\right)$ S. meine Untersuchungen über die Psalmen nach der Peschita p. $10 \mathrm{ff}$. - In der syrischen Psalmenhandschrift CXCI bei Wright, Catalogue of Syriac Manuscripts, wird Theodor als Urheber der In- 
Statt der eliminirten Ueberschriften der LXX hat Theodor seinen Erklärungen der einzelnen Psalmen selbständig mehr oder minder umfangreiche Inhaltsangaben ( $\left.\dot{v} \pi \circ \vartheta \vartheta^{\prime} \sigma \varepsilon \iota \varsigma\right)$ vorausgeschickt, welche in den Fragmenten zum Theil erhalten sind. In Bezug auf diese Inhaltsangaben wirft Leontius von Byzanz Theodor vor, er habe alle Psalmen in jüdischer Weise auf Zerubabel und Hiskia gedeutet und nur drei auf Christus bezogen ${ }^{1}$ ). Diese Behauptung ist aber in zweifacher Beziehung ungenau. $\mathrm{Zu}$ nächst sagt der Nestorianer Kosmas Indicopleustes, welcher sicher Theodor folgte, David habe vier Psalmen von Christus vorausgesagt, den 2., den 8., den 14., den 44. (45.) und den 109. (110.) $)^{2}$ ).

Auch in unserem syrischen Commentar werden diese vier und nur sie messianisch erklärt. Ferner hat Theodor jeden dieser vier Psalmen theilweise auf das göttliche, theilweise auf das menschliche Wesen Christi bezogen ${ }^{3}$ ); auch hierin stimmt der syrische Commentar mit Theodor überein. Ich gebe im Folgenden die Inhaltsübersicht dieser

haltsangaben genannt. Da keine Proben abgedruckt sind, läfst sich nicht sagen, ob sie mit den Ueberschriften in unserem Commentar übereinstimmen. Aber die im Catalog von Rosen und Forshall p. 11 abgedruckten, welche in der Handschrift ebenfalls Theodor zugeschrieben werden, sind dieselben wie bei unserem Nestorianer, und ebenso die anonymen bei Wright CLXVIII. Aufserdem hat Bar Hebraeus in seinen Scholien zu den Psalmen (herausgegeben von de Lagarde, Praetermissorum libri duo, 1879) sich diese Ueberschriften sämmtlich zu eigen gemacht, so dafs unser Manuscript durch ihn controllirt und vielfach vervollständigt werden kann. Wo im Folgenden einfach Bar Hebraeus citirt wird, sind immer seine Scholien zu den Psalmen gemeint. Genaueres über sein Verhältnifs zu unserer Handschrift folgt unten.

1) S. Kihn 1. 1. p. 454.

2) S. Fritzsche 1. 1. p. 35. Kihn 1. 1. hat die Differenz der beiderseitigen Angaben zu exklären gesucht.

3) Kihn 1. 1. 456. 
vier Erklärungen nach dem Syrer und verweise dabei zugleich auf die Parallelstellen in den Fragmenten.

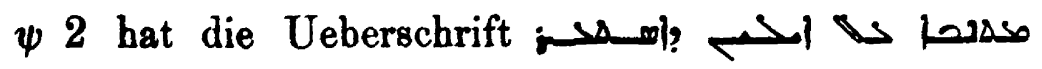
Weissagung auf das, was bei dem Leiden unsers Herrn von den Juden verübt wurde; zugleich erinnert uns der Psalm an seine Menschheit". In der Erklärung sind die v. 1 Herodes und Pilatus, die $\lambda a o i$ die Stämme der Jacobsöhne. Das „eitle Sinnen" besteht darin, dals sie meinen, wenn der Herr gestorben wäre, so werde er nicht wieder auferstehen. v. 2 „die Könige bezieht sich auf Herodes, die ă $\varrho \propto \nu \tau \varepsilon \varsigma$ sind die Schriftgelehrten und Pharisäer;,$b e-$ rathschlagten mit einander, dafs, wenn sie ihn am Leben liefsen, alle Menschen an ihn glauben würden. ${ }^{*}$ „Der Herr

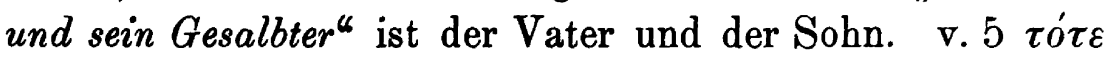
bezieht sich auf die Zeit nach der Himmelfahrt; „er wird sie schrecken durch das Schwert der Römer ${ }^{1}$ ), was sich vierzig Jahre nach seiner Kreuzigung erfüllte. ${ }^{\text {" }}$ จ. 6 , ich" $=$ Gott $;$ „meinen König $^{\alpha}=$ Christus. v. 7 ,damit er erzähle von meiner Satzung " (s. Pesch.) d. h. damit er verkündige das Evangelium vom Himmelreich. v. 7 , der Herr hat zu mir gesagt : du bist mein Sohn"; Glosse : „Dies sagt er aus der Person der Menschheit unsers Herrn“ (vgl. dazu Kosmas bei Kihn p. 456); ,heute habe ich dich gezeuget" ; Glosse : „Im Fleisch und in der Taufe und in der Auferstehung von den Todten (vgl. Kosmas ibid.) und in der Unsterblichkeit. ${ }^{*}$ จ. 8 „ die Völker zum Erbe statt des Volkes" [Israel]. v. 9 „du wirst sie weiden" (nach der

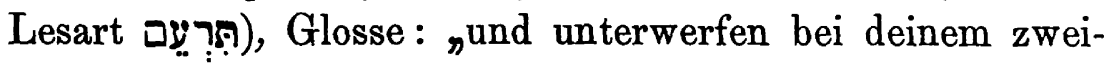
ten Kommen ... diejenigen, welche bei deinem ersten Kommen nicht glauben wollten.“ ${ }^{\circ}$ Und wie Töpfergefä $\int s e$,

1) Theodoret erklärt den eisernen Scepter v. 9 durch $\tau \tilde{\eta} \varrho \omega \mu \alpha \ddot{\varkappa} x \tilde{\eta}$ $\beta \alpha \sigma \iota \lambda \varepsilon l \alpha$. 
denen, wenn sie im Ofen gebrannt werden, alle Feuchtig-

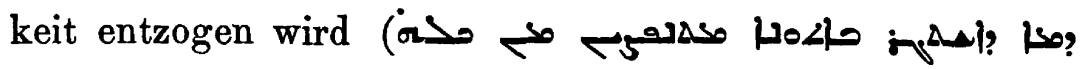

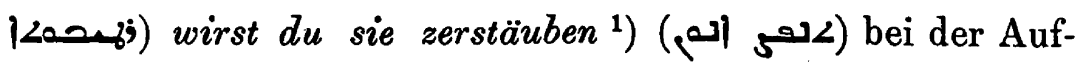
erstehung aus der Vergänglichkeit und dem Zustande

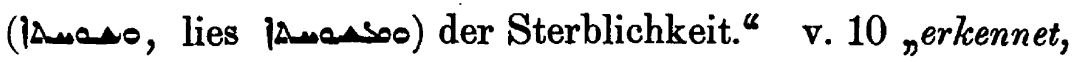
dafs ${ }^{2}$ ) der Herr des Reichs gekommen ist. ${ }^{*}{ }_{\text {La Last euch }}$ zurechtweisen ... durch das was von ihm oder von anderen in seinem Namen gethan ist." v. 12 „Küsset den Sohn, der durch eure Listen gefangen genommen wurde ${ }^{* 3}$ ) ( (a). „Sein Zorn wird bald entbrennen gegen die Juden, welche ihn gekreuzigt haben.“ „Die auf ihn trauen und auf sein Kommen harren."

$\psi$ 8, welcher von Theodor im Wortsinne auf Christus

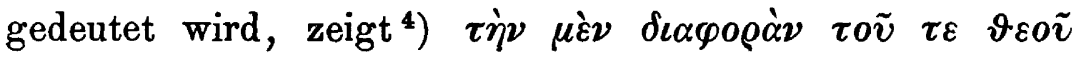

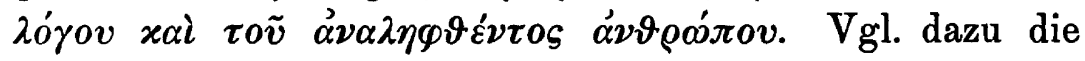
Uaberschrift im syr. Commentar كنص

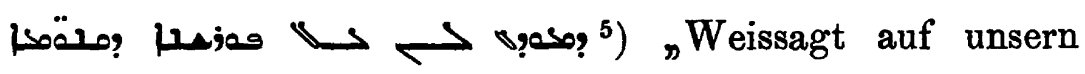
Herrn Christus und lehrt uns den Unterschied der Personen." v. 2 "Wie herrlich ist dein Name in allen Landen wenn dein Evangelium über den ganzen Erdkreis verbreitet wird." - Bei der Erklärung von v. 3 bezieht sich Theodor auf Matth. 21, 16 (Kihn 400, 456); ebenso fügt unser Commentar zu 3 a die Glosse : „beim Einzuge in

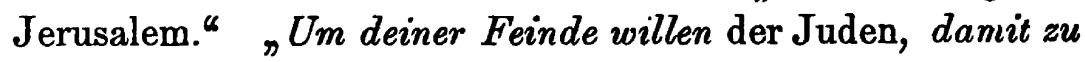
nichte werde ihre Anklage, und sie nicht sagen, die Volkshaufen preisen ihn aus Augendienerei. Der Feind der

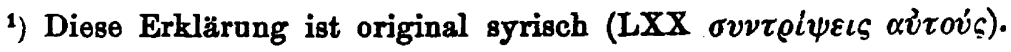

2) Ms. | 40 , lies | 4 ? .

8) Auch diese Glosse kann im griechischen Commentar nicht gestanden haben (LXX $\delta \varrho \alpha \xi \alpha \sigma \vartheta \varepsilon \pi \alpha \iota \delta \varepsilon l \alpha \varsigma)$.

4) S. Kihn p. 400 .

5) Lies $\$ 9060$. 
Jude, der an dir Rache nehmen will, als ob du gegen Gott und sein Gesetz wärest." (Vgl. Kosmas bei Kihn p. 456

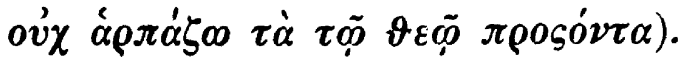

Von v. 5 an geht der Psalm nach Kosmas-Theodor auf den Menschen, welcher der grofsen Wohlthat der Annahme als Sohn gewürdigt worden ist (Kihn p. 456). Vgl. dazu die folgenden Erläuterungen aus dem syr. Commentar. v. 5 „Was ist der Mensch, da؟s du sein gedacht hast nachdem er in Irrthum verfallen war. ${ }^{*}-{ }_{n} D a \int_{s} d u$ dich seiner angenommen hast d. h. dafs du ihn aufsuchtest

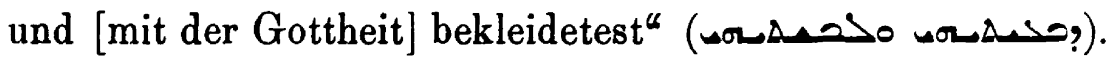
v. 6 „du hast ihn ein geringes unter die Engel erniedrigt wegen seines Todesleidens; mit Ehren hast du ihn zum Himmel fahren lassen und mit Schmuck der Unsterblichkeit und Herrschaft und Gottheit hast du ihn umhüllt." 7 „Werk deiner Hände d. h. die ganze Erde, welche früher widerspenstig war gegen deine Herrschaft. ${ }^{*}$. . . . v. 10 „auf der ganzen Erde in der Stunde deiner Offenbarung. ${ }^{*}$

Theodor's Erklärung von $\psi 45$ läfst sich aus Kosmas, Junilius, Facundus von Hermiane und Theodoret im Grofsen und Ganzen reconstruiren vgl. Kihn p. $457 \mathrm{ff}$., auf den ich für das folgende verweise, ohne die betreffenden Parallelen hier abdrucken zu lassen. Auch hier stimmt die syrische Erklärung fast überall genau mit den vorerwähnten Gewährsmännern überein. $\mathrm{Da}$ sie aber zugleich die Genannten in mehrfacher Hinsicht ergänzt und Theodor's Gedanken vollständiger wiedergiebt, so lasse ich hier eine vollständige Uebersetzung der Erklärung folgen.

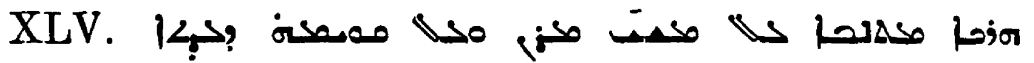

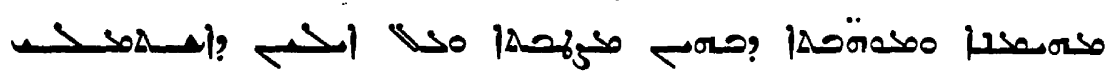
חHier weissagt er von unserem Herrn Christus und von dem Aufbau der gläubigen Kirche (cf. Junil. II 23 : ecclesiae spiritalem aedificationem), und den Gaben, mit welchen sie geschmückt wird, und von dem, was 
durch seine Heilsthat ( 6 = oixovopia = dispensatio $=$ Menschwerdung) vollbracht wurde.

2 Dichte, mein Herz $\left.{ }^{1}\right)$ d. h. ich rathe dir, dafs du hervorbringst, gute Worte; und sage meine Sachen dem Könige Christus; das sind seine Lehren und seine erhabenen ${ }^{2}$ ) Gaben. Meine Zunge ist der Griffel eines kundigen Schreibers d. h. des heil. Geistes. 3 Der Schönste an Ansehen ist unser Herr unter den Menschenkindern, nicht allein in Bezug auf die äufsere Gestalt, sondern auch durch seine Wunder und Grofsthaten, welche er vollbrachte. Huld ist ausgegossen auf deine Lippen, der du die Sünder umsonst rechtfertigst. Darum hat dich Gott für ewig gesegnet und hat bewirkt, dafs du dauernd von allen Menschen gepriesen werdest. 4 Lege das Schwert des Geistes d. i. das Wort Gottes an deine Lenden du Held, deins Herrlichkeit, die [dir] nach der Auferstehung wurde und deinen Ruhm und deine Kraft, die da siegreich ist ${ }^{3}$ ) und nicht besiegt wird. Sie [die Herrlichkeit?] besiegt den Ruhm der Wunder, die du vor deinem Leiden vollbracht hast. 5 Fahr einher gekreuzigt wegen des Wortes der Wahrheit des Evangeliums, welches du in die Welt säest und der vollkommenen Demuth der Gerechtigkeit, welche du lehrst. Dein Gesetz in der Furcht deiner Rechten ${ }^{4}$ ) sendest du in die Welt durch neue Wunder, welche du vollführst, der du nicht bedarfst der Hülfe Anderer. 6 Deine Pfeile (d. i. die Strafe), durch welche die Juden von den Römern ge. tödtet und vernichtet werden, sind geschärft und die Völker,

1) S. o. S. 59 .

2) مكلته|

s) sie והדרך v. 5 ausläfst.

4) Ich mache noch einmal darauf aufmerksam, dafs der Verfasser überall die Peschita zu Grunde legt. 
welche du gewinnst, werden in Folge deiner Worte im Glaubensgehorsam vor dir viederfallen. Geschärfte Pfeile werden die genannt, welche mit Spitzen und Stacheln von Eisen versehen sind; und diese Pfeile werden eindringen in das Herz der Feinde des wahrhaftigen Königs ; jene Feinde sind der Tod und der Satan und seine Diener. 7 Dein Thron und dein Reich, o Gott, besteht für immer und ewig und über Alles herrschest du; ein gerades Scepter, an dem kein falsch (sمار), ist das Scepter deines Reichs. Er entnimmt das Bild von den Königen, welche einen Herrscherstab (2م) oder etwas ähnliches in der Hand halten. $8 D u$ liebtest Gerechtigkeit, nämlich dafs sie in den Herzen der Menschen ausgesäet werde; und hafstest Gottlosigkeit, d. h. $\mathrm{du}$ wolltest sie aus ihren Seelen ausrotten; deswegen, weil $\mathrm{du}$ diese Absicht hattest, hat dich gesalbt Gott dein Gott durch den heiligen Geist mit Freudenöl um die Völker zu beleben, mehr denn deine Genossen, die Könige im Gesetz, welche mit Oel der Priester gesalbt wurden. 9 Myrrhen und Kassia zu deiner Einbalsamirung und Stakte (der berühmte Wohlgeruch, der nach deinem Leiden auf dem ganzen Erdenkreise sein sollte; er deutet aber mit dieser Einbalsamirung auf das was Nikodemus brachte) erfreuen alle deine Kleider d. i. deinen Leib, in welchem wie hinter dem Vorhange die göttliche Natur verborgen und vor den Blicken verdecket ist ${ }^{1}$ ). Aus herrlichem Tempel (Hea) von mir, Gott, her erfreuen dich, Christus, alle Völker, welche Tempel auf deinen Namen bauen, und auftreten und dich preisen durch ihr rühmliches Betragen. Mit dem einen Tempel nämlich deutet er die vielen an. 10 Die Königstochter steht in Herrlichkeit und Gnadenfülle und Ehre, welche den Heiligen aufbewahrt ist. Köngstochter aber

1) Vgl. hierzu Kihn p. 194 . 
nennt er die Kirche wegen der Neugeburt aus der Taufe, und König Christus. Und die Königin zu deiner Rechten mit grofser Ehre und mit Herrlichkeit habe ich sie umhüllt bei der Auferstehung, wie geschrieben steht (Matth. 25, 33) $₫$ und wird die Schafe zu seiner Rechten stellen. «" Königin nennt er die Kirche weiter, weil sie durch feste Liebe in wahrem Glauben mit Christus verbunden ist. Mit einem Gewand von Ophirgold bekleidet und geschmückt. Mit Gewand meint er die Gnade des Geistes, welche die Heiligen anziehen, und die Wunder, welche durch sie vollbracht werden, wie das Gold, welches von Ophir kommt, das vorzüglichste an Schimmer

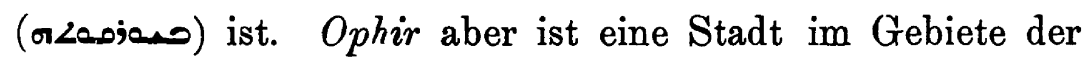
Kuschiten. 11 Höre Tochter, o Kirche, die Stimme des Bräutigams, und sieh, was er für dich ertrug, und neige dein Ohr seine Lehre zu hören, und leihe dein Gehör nicht den Fremden, und vergils dein Volk und dein Vaterhaus, und entferne dich von ihren früheren Gewohnheiten, da du die Götzen anbetetest. Mit dem Ausdruck dein Volk und dein Vaterhaus meint er alle Völker, aus welchen die Kirche gesammelt ist, ob Juden oder Heiden. 12 So wird der König Lust haben an deiner vollkommenen Schönheit und an den Tugenden und am Glauben. Denn er ist dein Herr, bete ihn an als Herrn, und schäme dich nicht der Schmach seines Leidens. 13 Und die Tochter Tyrus, eine mächtige, durch ihren Reichthum und Stolz berühmte Stadt, wird anbeten, bei seiner Offenbarung, wenn sie seine Herrschaft anerkennt. Mit Gaben werden dein Antlitz suchen die Reichen des Volks; um zu dir gezählt und mit dir vereinigt zu werden wegen der Ehren und Wohlthaten, welche dir von ihm erwiesen werden. 14 Ganz herrlich ist die Königstochter inwendig, im Verborgenen; [damit meint er] die Tugend der Seele und die Reinheit des Gewissens, deren wegen die Edlen werden gepriesen werden. Und 
geschmückt ist ihr Kleid mit gutem Golde d. i. die geistige Gabe, welche in der Taufe gegeben wird, und die Keuschheit und der Strahlenglanz. 15 Mit Gaben der Seele wird sie zum Könige, ihrem Bräutigam, gelien, um von ihm ge-

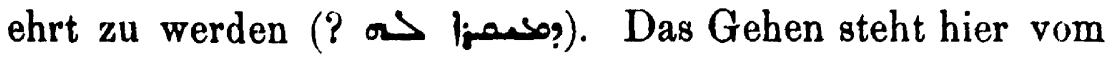
Eilen der Gedanken. Und sie werden bringen Jungfrauen, die sich in dem Stande der Jungfräulichkeit befinden, ihre Gespielinnen, hinter ihr her. Sie werden bringen (נهذم) zu Christus das Werk (llos), welches sie in der Kirche durch die Jungfräulichkeit vollbracht haben, ob sie nun Männer oder Weiber sind. Auf den Stand der Frauen aber hat er die Jungfräulichkeit bezogen in Gedanken an die Königin, insofern ihnen die Keuschheit und Milde noch besser ansteht als den Männern. 16 Und werden kommen mit Freuden und nicht mit Zwang, und Wonne und nicht in Trauer über dies Versprechen der Jungfräulichkeit, das sie zu erfüllen haben. Um einzugehen in des Königs Palast, in das Gemach, in welches die klugen Jungfrauen gingen. 17 An Stelle deiner Väter, o Kirche (das sind aber die Priester aus dem Hause Aron und die heidnischen Priester und Beschwörer); werden deine Kinder treten, die aus dir geboren werden, die Priester und Lehrer der Wahrheit, welche aus dem Volke [Israel] und den Völkern aufgestellt sind. Mache sie zu Gewaltigen in der ganzen Welt, zu binden und zu lösen im Himmel und auf der Erde, über jeden der an Christus glaubt. 18 Damit wir deines Namens gedenken, o Christus; wir, die Christen, nämlich dals wir dir Priesterdienste thun, von Geschlecht zu Geschlecht, indem wir unveränderlich bleiben in der Liebe zu dir. Darum werden dir die Völker danken von Ewigkeit zu Ewigkeit, für dein Kommen im Fleisch, für die Erlösung der Völker, für die Erwählung der Kirche und für die gute Hoffnung, welche durch dich allen Menschen gegeben ist." 
Der vierte und letzte Psalm, welchen Theodor ${ }^{1}$ ) und mit ihm unser Commentar direct auf Christus beziehen, ist der 110. Er führt im Commentar die Ueberschrift „Weissagt auf die Heilsthat (oixovouia) Christi." v. 3 geht nach Theodor auf die Gottheit (vgl. Junilius II 22 aut divinitatis eius generationem ante principium ut est ${ }_{\text {ex }}$ utero ante luciferum ${ }^{2}$ ) genui $\left.t e^{(}\right)$. Ebenso unser Commentar : „Im heiligen Schmucke der Gottheit. Aus dem Mutterleibe der Taufe wird dir dieses herrliche Volk erstehen. Oder folgendermafsen : Im heiligen Schmuck von Mutterleibe an, d. h.

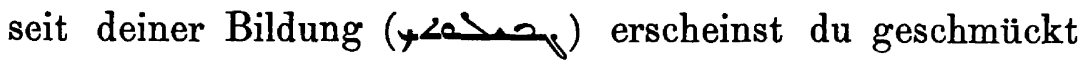
und heilig. Und so führt er an (مكدן; vgl. Kosmas :

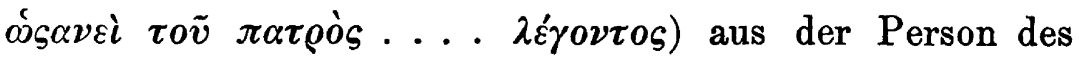
Vaters und spricht : vor Alters (مب مبر) habe ich dich

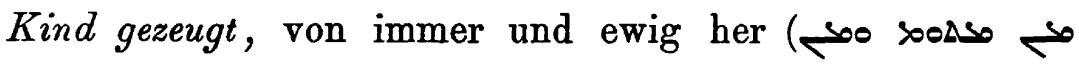
s)."

Das Priesterthum Christi nach der Weise Melchisedeks v. 4 wird daraus erklärt, dafs dieser sein Priesterthum nicht auf andere vererbte ( إl) und nicht Opfer von Thieren darbrachte, sondern Brot und Wein. v. 5 „Der Herr ist zu deiner Rechten und vollendet durch dich die ganze Heilsökonomie zur Erlösung des All's." „Die Könige, welche

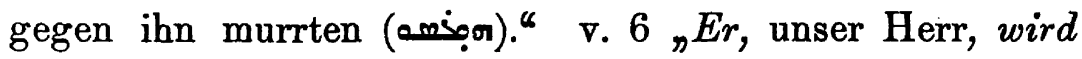
richten die Völker beim jüngsten Gericht, und wird anfüllen die Hölle mit ihren Leichnamen, und wird abschlagen das Haupt Vieler im Lande der Verheifsung durch das Schwert der Römer, welches bei der Zerstörung Jerusalems nach der Himmelfahrt des Herrn über die Juden kam."

1) S. Kihn 1. 1. 402.457.

2) S. für diese und die folgenden Lesarten meine Abhandlung : Der textkrit. Werth u. s. w. zn der Stelle. 
Das „Trinken aus dem Bach“ *. 7 wird bezogen auf die Zeit, da Christus in der Wüste und Einöde und auf den Bergen umherzog und das Evangelium vom Reiche verkündigte. Darum, wegen dieses Leidens der Erniedrigung, welches er auf sich nahm, wird sein Haupt erhoben werden bei der Auferstehung und wird er offenbart werden in der Ehre der Gottheit und wird Himmlischen und Irdischen als Sohn Gottes offenbar werden."

Die Abhängigkeit des Syrers von Theodor bewährt sich nun aber nicht allein darin, dals beide die genannten vier Psalmen messianisch auslegten, sondern auch darin, dals er die von Theodor im Gegensatz zur kirchlichen Auslegung nicht messianisch gedeuteten Psalmen ebenfalls genau in der Weise seines Vorgängers auffalst. Hierher gehören zunächst die Psalmen 16. 22. 69.

Nach Kosmas Indicopleustes, welcher sich eng an Theodor anschlielst, hat Theodor nur die Psalmen 2. 8. 45. 110 direct auf Christus gedeutet; alle anderen Stellen aus den Psalmen, welche im neuen Testament auf Christus bezogen werden, sind nicht als directe Aussagen über ihn

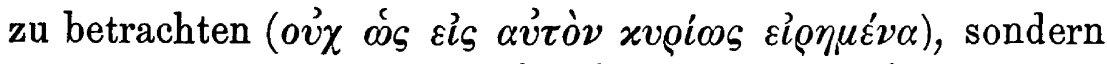

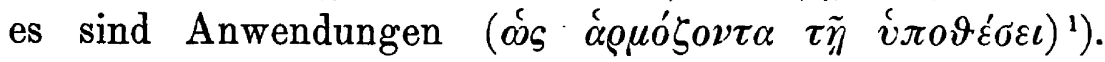
Theodor selbst hat jedenfalls in seinen späteren Schriften in solchen Stellen auch „Typen " erblickt, d. h. „vom heiligen Geist intendirte gottgewollte Vorbilder neutestamentlicher Gegenbilder " 2). Fritzsche erklärt l. l., in den Fragmenten des Psalmencommentars keine Spuren dieser typischen Erklärung gefunden zu haben und schliefst daraus, dafs Theodor erst in späterer Zeit durch dies Mittel das alte Testament mit dem neuen enger zu verbinden getrachtet habe. Was Kihn p. 160 für die typische Auslegung der drei genannten Psalmen durch Theodor beibringt, ist nicht

1) S. Fritzsche 1. 1. 37.

2) S. Kihn 1. 1. $153 \mathrm{ff}$. 
beweisend. Die vom fünften ökumenischen Concil verworfenen typischen Erklärungen. Theodors zu den Psalmen 16. 22. 69 sind dem Widmungsschreiben zum Commentar über die zwölf kleinen Propheten entnommen ${ }^{1}$ ); es steht aber fest ${ }^{2}$ ), dafs Theodor in späterer Zeit theilweise andere exegetische Grundsätze befolgte als bei der Ausarbeitung des Psalmencommentars. Auf alle Fälle hat Theodor auch noch im Commentar zu den kleinen Propheten die genannten drei Psalmen in erster Linie historisch erklärt; die Antwort auf die Frage, ob er auch schon im Psalmencommentar die typische Auslegung befolgte, ergiebt sich aus dem Syrer.

$\psi 16,10$ versteht Theodor historisch von der Errettung des auserwählten Volkes aus Gefahr und Verderben ${ }^{3}$ ). So auch der syrische Commentar. Ueberschrift : مرحدم وخطا Gebet des Volks um Errettung aus dẹn Bedrängnissen, von denen es umgeben war." Dieser Ueberschrift entsprechend wird „der Heilige" v. 10 als das Volk Israel erklärt. „Der Hölle überlassen“ heifst : „von Bedrängnifs verschlungen werden lassen. ${ }^{*}$ $\mathrm{Zu}$ den Worten : „Verderben sehen " findet sich die Glosse : „durch seine Feinde." Von einer typischen Erklärung oder Bezugnahme auf das neue Testament ${ }^{4}$ ) findet sich im syrischen Commentar keine Spur.

$\psi 22$ bezieht Theodor geschichtlich auf David, indem er ausführt ${ }^{5}$ ): Quod enim psalmus nullatenus convenit domino certum est. Neque enim erat domini Christi, qui peccatum non fecit, nec inventus est dolus in ore eius,

1) S. Kihn 1. 1. 54.

2) S. Fritzsche 1. 1. 36 .

s) Kihn I. 1. 160.

4) Hoc verum eventum in ipsis rebus accepit nunc in domino Christo. Theodor bei Kihn 1. 1.

5) Kihn 1. 1. 161. 
dicere : longe a salute mea verba delictorum meorum. Sed et ipse dominus dum secundum communem hominum legem in passione opprimeretur, ndeus meus, deus meus, quare me dereliquiste" emisit vocem, et apostoli „diviserunt sibi vestimenta mea et super vestimentum meum miserunt sortem" ad eum traxerunt (" supra modum dictum fuerat prius a David propter illata ei mala, hoc ex operibus evenit in domino Christo, cuius et vestimenta diviserunt et sorti tunicam subjecerunt. Vgl. dazu den syrischen Commentar. Ueberschrift : $\sigma<\mathrm{C}_{3}$ „Gebet Davids als er von Absalom verfolgt wurde. ${ }^{*}$ v. 2 „Warum hast $d u$ mich verlassen " Glosse : „dafs ich durch Absalom geprüft werde."

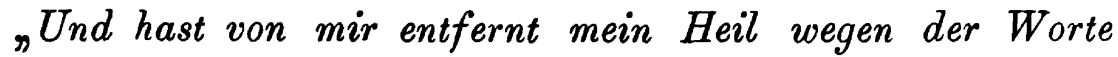
meiner Thorheiten ${ }^{*}{ }^{1}$ ); Glosse : „da ich gegen dich gesündigt habe." 4 „Du bist heilig" ; Glosse : „Ich aber bin ein Sünder." „Die Hunde" v. 17 sind die Anhänger Absaloms, die wegen ihrer Frechheit so genannt werden. v. 18

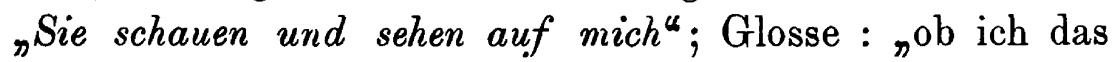
hätte, was sie suchen " (vgl. Kihn l. l. omnia perscrutabantur etc.) v. 22 Der ${ }_{n}$ Löwe" und das „Einhorn" ist wieder Absalom; der ${ }_{\text {A Arme }}$ " v. 25 ist David, die „Elenden" v. 27 sind die, welche bei ihm waren u. s. w. Auch hier findet sich durchaus keine Beziehung auf das neue Testament.

$\mathrm{Zu} \psi 69$ ist die Inhaltsangabe Theodor im Original

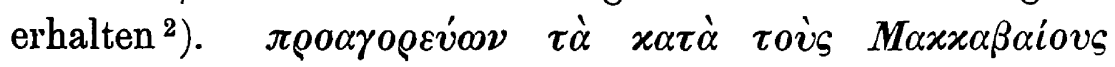

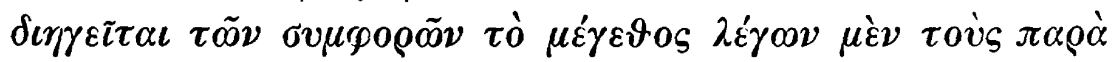

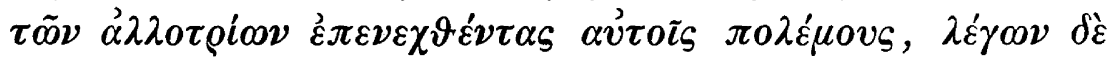

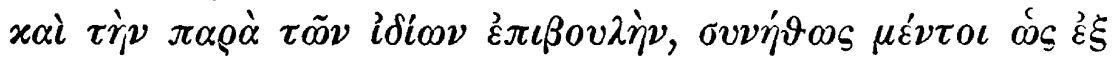

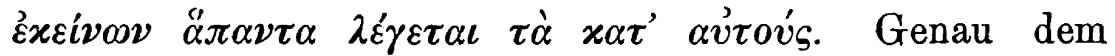

1) Uebersetzung der Peschita, die hier mit LXX ziemlich genau übereinstimmt. S. meine Abhandlung ${ }_{n}$ Der textkritische Werth etc." zu der Stelle.

2) S. Cord. II 395 . 


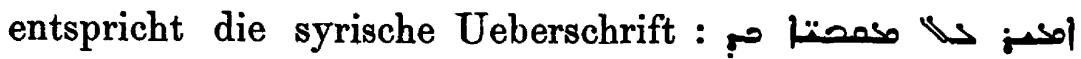
v. 5 ${ }_{n}$ Zahlreicher als die Haare meines Hauptes sind meine Feinde, die Leute des Antiochus, die ohne Ursache mit mir Krieg führen, und stärker als meine Knochen ${ }^{1}$ ) sind die, welche mir unbillig feind sind im Volke, sie die mit 120000 gegen mich zogen um mich zu fangen. Was ich nicht geraubt habe muґs ich bezahlen, das Geld, das sie mir auferlegt haben und die heiligen Gewänder, die sie mir raubten." ich Schmach von Seiten der Macedonier, weil ich ihre Götzen nicht angebetet habe, und bedeckt Schain mein Angesicht, weil sich auch von meinen Volksgenossen viele zusammengethan und den Fremden angeschlossen haben. v. 9 Ich bin fremd geworden meinen Brüdern, die sich vergangen haben und Heiden geworden sind, und ein Fremdling für meiner Mutter Kinder, welche die Unreinigkeit der Heiligkeit vorgezogen haben ${ }^{2}$ ). v. 10 Der Eifer um dein Haus hat mich verzehrt, als ich den Altar auf den Namen des Götzen Zeus in seinem Inneren stehen sah u. s. w. ${ }^{*}$ v. 15 „Der Koth des Heidenthums." Zu v. 22 "sie gaben mir Essig zu trinken" findet sich nur die Glosse :

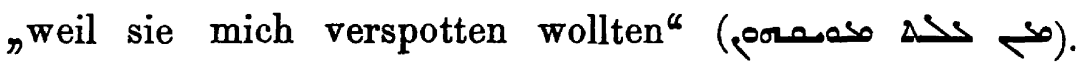
v. 27 „Denn sie verfolgen, den du geschlagen hast, nämlich uns, wegen unserer Sünden." Also auch hier keine Bezugnahme auf das neue Testament.

Man sieht nicht ein, warum sich das fünfte ökumenische Concil darauf beschränkte, die historischen oder historischtypischen Erklärungen Theodors zu den drei zuletzt besprochenen Psalmen zu verurtheilen; dasselbe Urtheil hätte

1) Nach der Lesart מתומעy.

2) Vgl. bei Kihn 1. 1. 161 : de judseis dicta sunt plura, qui se separaverunt de deo et lege convincentia illorum inderotionem. 
die Psalmen 68. 72. 89 treffen müssen, die ebenfalls von Theodor wie von unserem Syrer historisch gedeutet werden. Aus 68 und 72 sind schon oben S. 65 Belege hierfür angeführt; hier noch einige Nachträge.

$\psi 68$ hat im syrischen Commentar die Ueberschrift

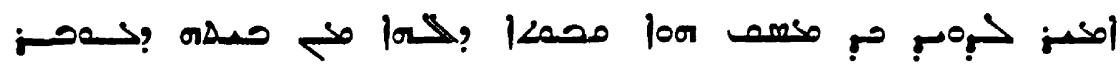
LA \ool „Gesprochen von David als er die Lade Gottes aus dem Hause des Gathiters Obed Edom heraufführte. ${ }^{*}$ Dies ist ein Excerpt aus der ausführlichen Inhaltsangabe Theodors bei Corderius II $335 \mathrm{f}$., vgl. besonders die Worte :

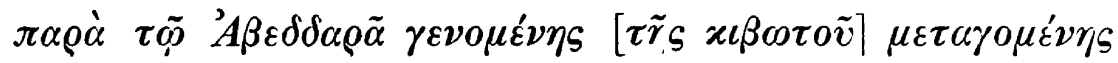

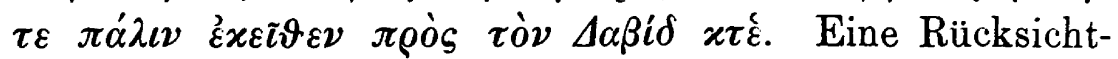
nahme auf Ephes. 4, 8 findet sich bei dem Syrer zu v. 19 nicht.

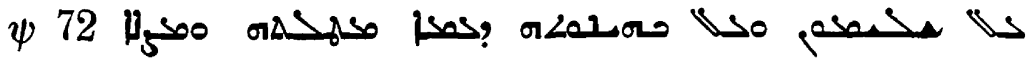
Auf Salomo und auf den glücklichen Zustand des Volkes um seinetwillen; David betet, dals ihm die Güter vollständig möchten erhalten werden." Genau so Theodor im Commentar zu

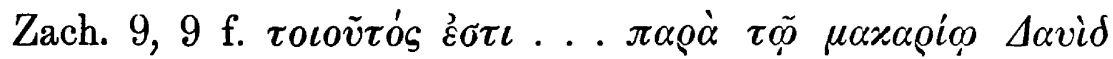

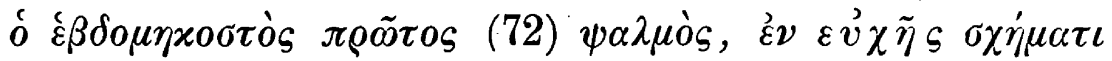

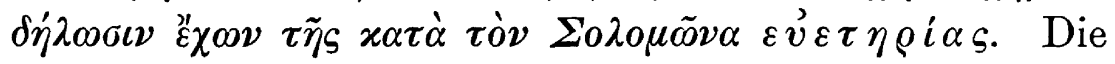
Polemik gegen die messianische Auffassung des 17. Verses ist bereits oben mitgetheilt; der Syrer erklärt dann auch noch ausdrücklich, dals die folgenden Worte un nicht passivisch, sondern reflexiv zu fassen seien : נهمه

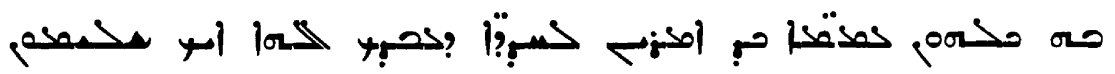
„Segnen sollen sich bei ihm alle V̌ölker, indem sie zu einander sagen : Gott mache dich Salomo gleich." Auch hier tindet sich bei dem Syrer durchaus keine Beziehung auf das neue Testament.

Die einzigen beiden Psalmen, welche vom Syrer historisch und messianisch zu gleicher Zeit erklärt werden, 
sind der 89. und 118. Hier sind die Erklärungen der Art, dals es den Anschein gewinnt, der Psalm solle eine directe Weissagung auf Christus sein, oder wenigstens als liege eine Mischung des Historischen und Prophetischen im Wortlaute des Psalms vor. 89, 5 wird folgendermalsen umschrieben : „Ich will ewiglich deinen Samen bestätigen, das sind die Könige, die von dir kommen, und will bauen deinen Thron für und für d. i. Christus im Fleisch." v. 29 f. „mein Bund soll ihm fest bleiben, und seinem Ge. schlecht. Ich will ihm ewiglich Samen geben. Dies geht auf die Menschheit unseres Herrn, der von seinem Samen stammt. ${ }^{\circ}$ Aber auch hier bewährt sich die Uebereinstimmung des Syrers mit Theodor. Der Psalm führt die

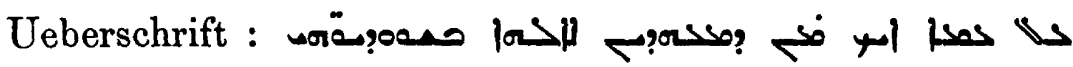
ب. Das ist die etwas verkürzte sonst aber buch-

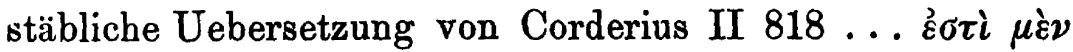

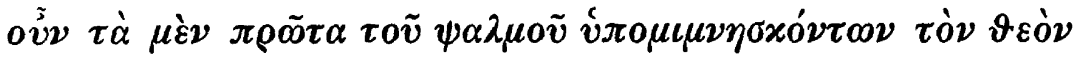

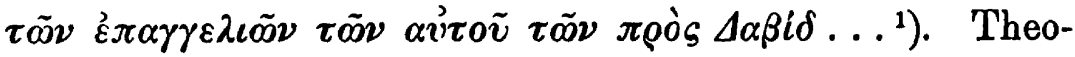
dor hat diesen Psalm sodann aber in der Weise ty pis chmessianisch erklärt, dafs er jede andere Erfüllung der Prophetie auf das bestimmteste in Abrede stellt ${ }^{2}$ ).

Die Ausdrücke im Commentar zu Micha 5, 2 decken

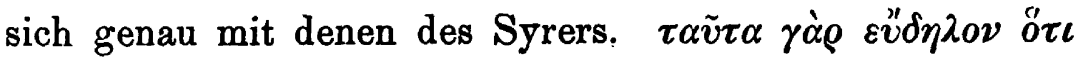

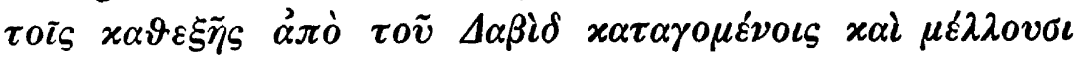

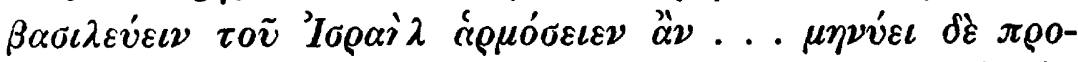

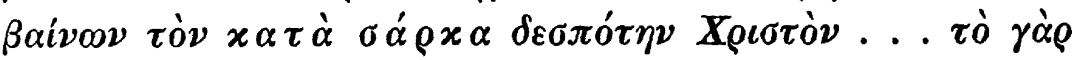

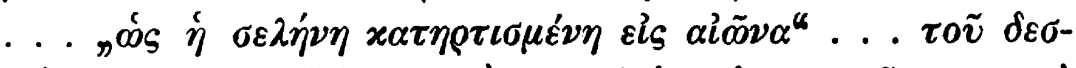

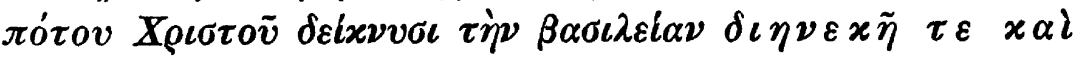

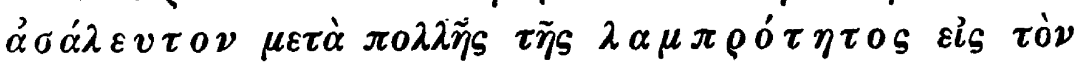

1) Bei Corderius werden diese Worte Diodor zugeschrieben; sie gehören aber, wie sich aus dem Syrer ergiebt, Theodor an.

2) Vgl. Kihn 1. 1. 150.

Zeitschrift f. d. slttest. Wiss. Jahrgang 5. 1885. 


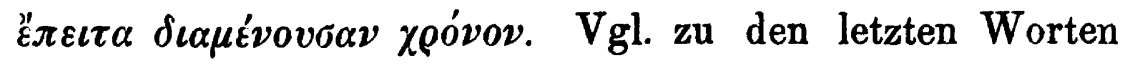

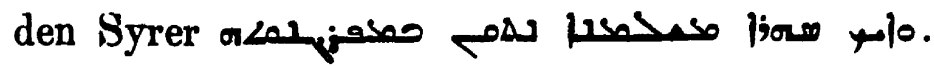

Aehnlich wird man nun über $\psi 118$ zu urtheilen haben.

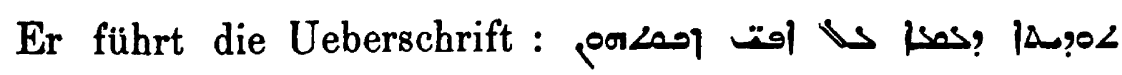
„D Dank des Volkes für den Sieg nach ihrer Rückkehr [als sich die umwohnenden Völker gegen sie versammelten sammt Gog und Magog, und sie dieselben überwunden hatten ${ }^{1}$ ). v. 22 nun wird der "Stein ${ }^{\text {" }}$ auf Christus gedeutet, und hinzugefügt : ${ }^{\text {von }}$ hier an und weiter bezieht er seine Weissagung auf unsern Herrn und die Gläubigen." Aber dies ist offenbar eine Verkürzung und Verstümmelung der typischen Auslegung Theodors. Letzterer hat, wie aus Bar Hebraeus zu ersehen ist, den "Stein" auf Zerubabel gedeutet; die Bauleute sind freilich auch in unserem Commentar die Priester und Aeltesten, aber bei Bar Hebr. zugleich „die Diener des Perserkönigs, welche aus Babel geschickt waren, um Jerusalem zu bauen; weil sie aber einen Streit mit Zerubabel hatten, wurde der Bau lange verzögert." Erst dann fügt Bar Hebr. hinzu : „diese Worte werden auch geistlich

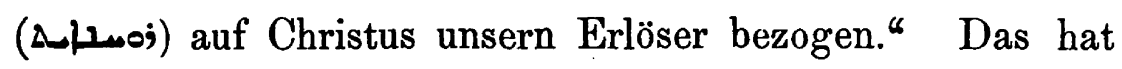
aber auch schon Theodor gethan, wie sich aus Cord. III 359. 363 ergiebt, zwei Fragmenten, die Fritzsche p. 31 mit Unrecht Theodor absprechen will.

Die sachliche Uebereinstimmung des Syrers mit Theodor in Bezug auf messianische Psalmenauslegung hat sich ausnahmslos bewährt. Freilich hat er seinen Gewährsmann aufserordentlich verkürzt oder vielmehr ziemlich dürftig

1) Die eingeklammerten Worte sind nur bei Bar Hebraeus erhalten; aber im Psalm selbst (v. 21) wird Gog auch von unserem Epitomator erwähnt. 
excerpirt; aber in diesem Excerpt sind die charakteristischen Ausdrücke Theodors immer wiederzuerkennen, und da von dem griechischen Commentar nur Fragmente erhalten sind, so bietet der Syrer hin und wieder nicht zu unterschätzende Beiträge zur Bereicherung der Kenntnifs von Theodors Exegese. Alles dies gilt auch von dem übrigen Theil des syrischen Commentars.

Leontius von Byzanz hatte Theodor vorgeworfen ${ }^{1}$ ), dafs er mit Ausnahme von drei (richtiger vier) messianisch erklärten Psalmen alle übrigen in jüdischer Weise historisch auf Hiskia und Zerubabel gedeutet habe. Auch der zweite Theil dieser Behauptung ist nicht genau. Zunächst nämlich berichtet Facundus von Hermiane ${ }^{2}$ ), ,impugnatores s. synodi (Chalced.) ob hoc de illo ista iactare, quod in interpretatione Ps. quaedam moralit er exposuisse dicatur, quae in Christum magis dicta debent intelligi." Es fand sich also in Theodor's Commentar neben der historischen und messianischen Deutung der Psalmen auch eine ethische. Sogleich wird sich zeigen, wie dieser Bericht durch Kosmas Indicopleustes bestätigt wird. Weiter aber ist aus den griechischen Fragmenten ersichtlich, dafs Theodor allerdings viele Psalmen historisch gedeutet hat, aber nicht allein auf Hiskia und Zerubabel, sondern auch auf die Geschichte Davids und besonders auch auf die der Makkabäer. Genauer lernt man daher Theodors Classificirung der Psalmen aus Kosmas Indicopleustes kennen, der, wie mehrfach bemerkt, sich eng an Theodor anschliefst. Er

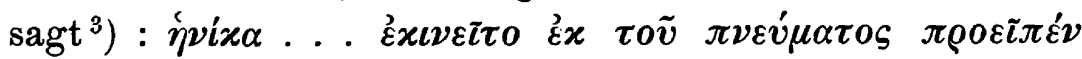

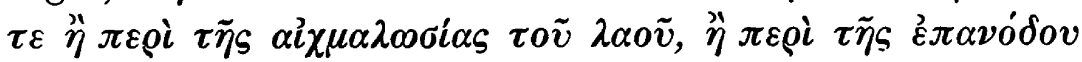

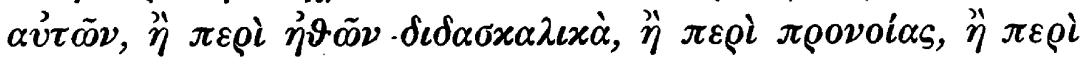
$\tau o \tilde{v} \delta \varepsilon \sigma \pi \hat{\tau} \tau o v$ X $\varrho \iota \tau \sigma \tilde{v}$.

1) S. oben \$. 67 .

2) Bei Fritzsche 1. 1. p. 36.

3) Bei Fritzsche 1. 1. p. 35. 


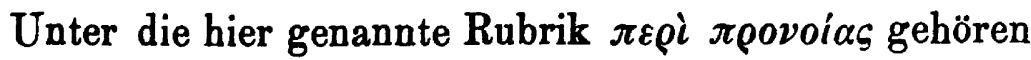
im syrischen Commentar die folgenden Psalmen.

4.

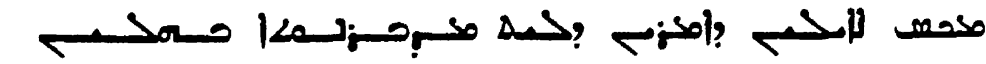

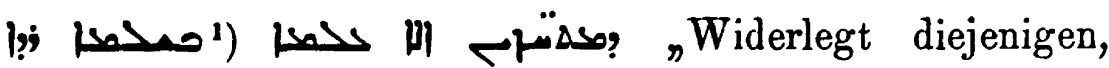
welche sagen, dafs keine Regierung in den Erscheinungen herrscht, sondern dafs die Welt in Wirren ( $\tau \alpha \rho \alpha \chi \omega \delta \delta \tilde{a} \varsigma$ ?)

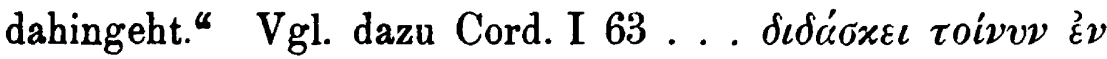

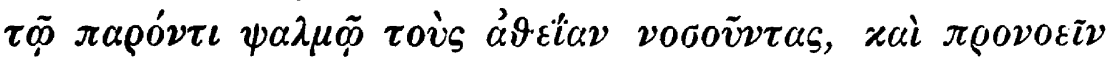

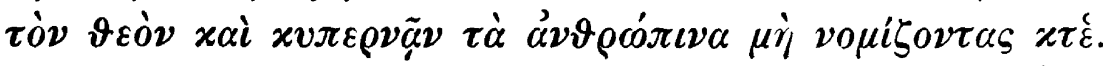

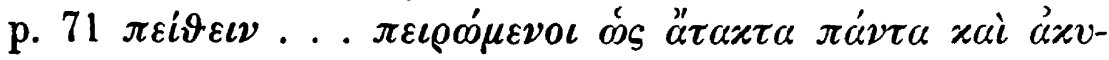

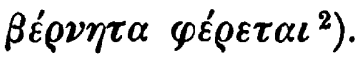

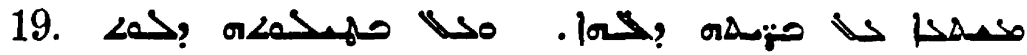
„Erzählt von den Schöpfungen Gottes und von seiner Fürsorge für die Menschen."

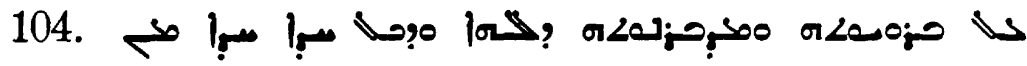
„Von der Schöpfung und Regierung Gottes, und dal's jedes einzelne von seinen Geschöpfen wunderbar zubereitet ist."

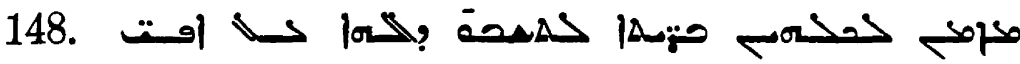
ص Fordert alle Geschöpfe zum Preise Gottes auf wegen seiner Handlungsweise gegen jedes."

Für die letztgenannten drei Psalmen liegen griechische Fragmente zur Controlle nicht vor; der stricte Beweis, dafs auch diese Inhaltsangaben auf Theodor zurückgehen, mufs daher vorläufig noch ausgesetzt werden. Dasselbe gilt für die meisten Psalmen der Classe, welche nach

1) Lies thar Hebr.).

$\left.{ }^{2}\right)$ Diese Stellen gehen allerdings nicht direct auf Theodor zurück, sondern auf Theodoret; aber der letztere bat sich hier offenbar, wie z. B. auch $\psi 45$ (s. 0.), ziemlich wörtlich an seinen Lehrer gehalten. 


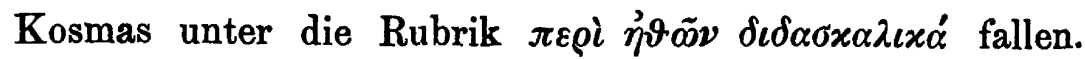
Es sind im syrischen Commentar die folgenden zwölf ${ }^{1}$ ).

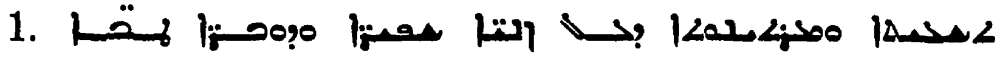
${ }_{n}$ Anleitung $\left(\dot{\varepsilon} \xi \eta_{\eta} \gamma \sigma \iota \varsigma\right)$ und Vermahnung zu guten Sitten und trefflichem Benehmen."

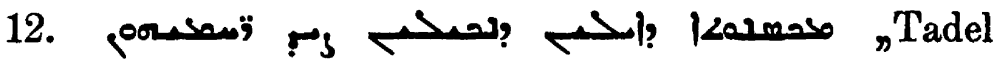
derer, welche hinterlistig glgegen ihre Freunde sind."

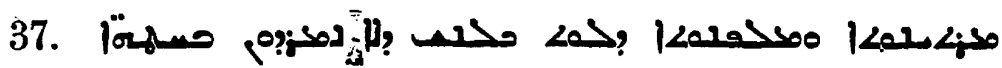
„Vermahnung und Belehrung aller Menschen, nicht in Sünden zu verfallen."

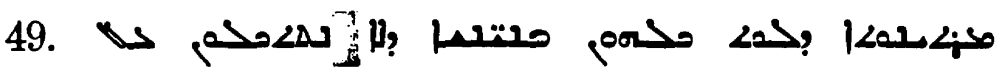
Nermahnung aller Menschen, nicht auf den Reichthum und die Herrlichkeit der Welt zu vertrauen.

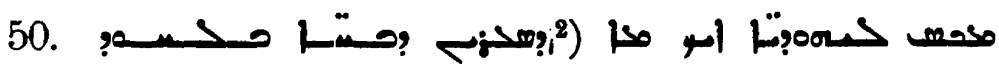

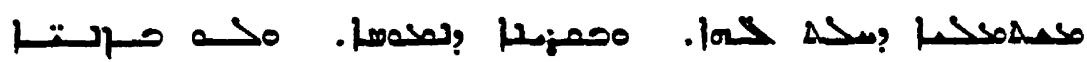
Tadelt die Juden, weil sie meinten, dafs in Opfern allein die Gottesfurcht zur Ausführung komme und im Lesen des Gesetzes, und nicht durch die Eigenschaften des Charakters und [gutes] Verhalten ${ }^{3}$ ) [indem sie] sonst die Tugend verachteten."

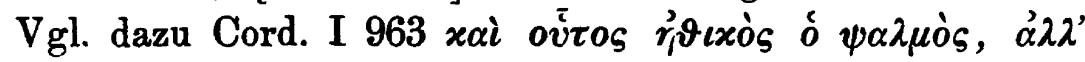

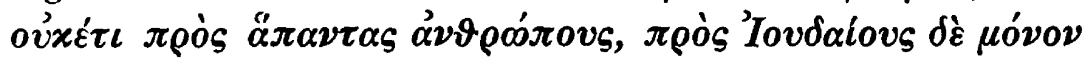

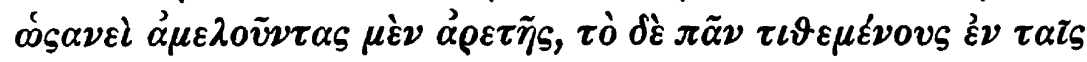

1) Da Theodor auch den historisch gedeuteten Psalmen doch immer zugleich eine park̈netische Bedeutung zuerkennt (Cord. I $574 \varepsilon \dot{\varepsilon} \tau \tilde{\omega} v$

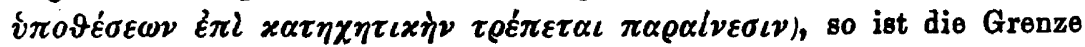
zwischen ethischen und historischen Psalmen allerdings keine ganz feststehende. Zu den ersteren werden die zu rechnen sein, in denen überhaupt keine historischen Beziehungen rorkommen.

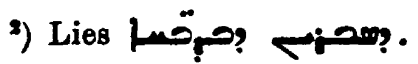

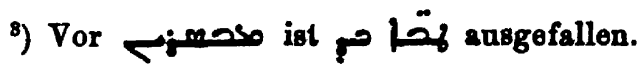




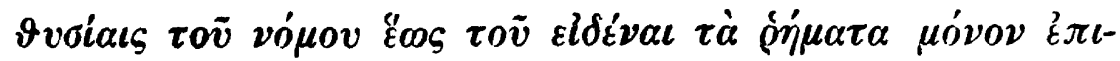

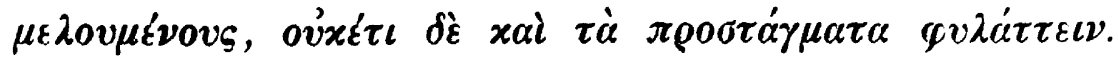

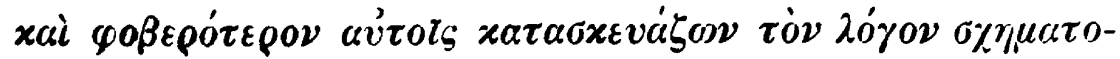

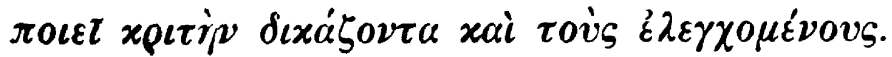

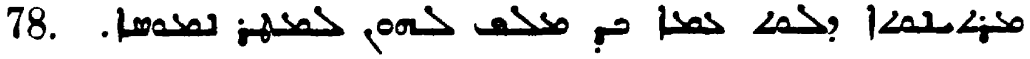

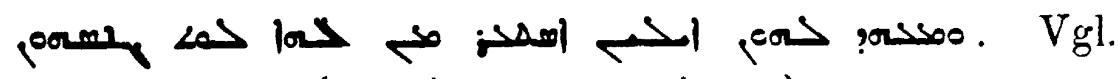

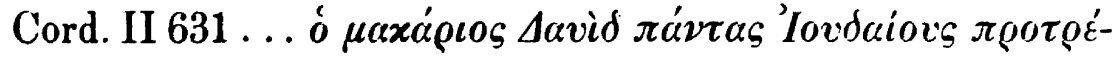

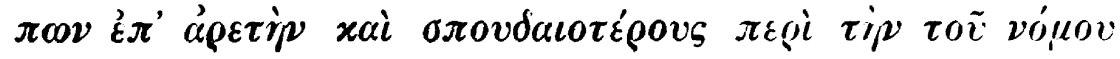

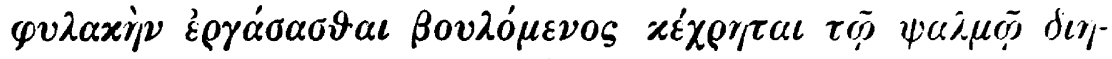

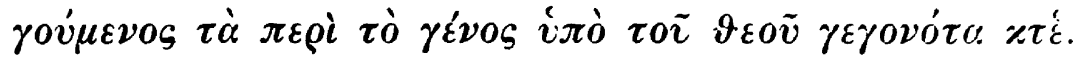

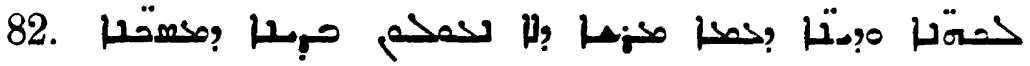
„Mahnt die Priester und Richter des Volks, beim Gericht der Armen nicht ungerecht zu sein."

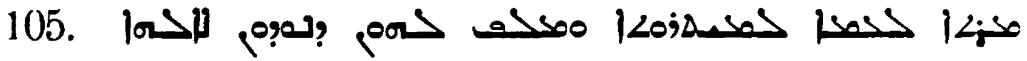

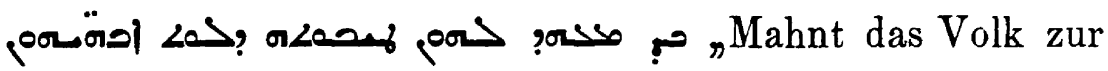
Tugend und lehrt sie Gott zu danken, indem er sie an seine Gnade gegen ihre Väter erinnert."

112. مار مermahnung aller Menschen, auf die Tugend bedacht zu sein."

113. Ermahnet das Volk, Gott Loblieder anzustimmen."

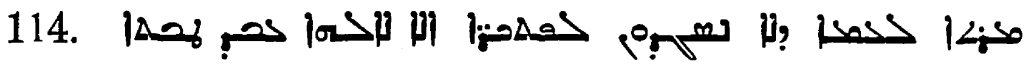
محأ Mahnt das Volk, nicht den Götzen zu dienen, sondern Gott, dem Wohlthäter Aller."

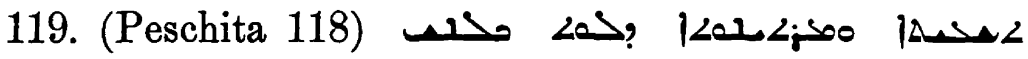

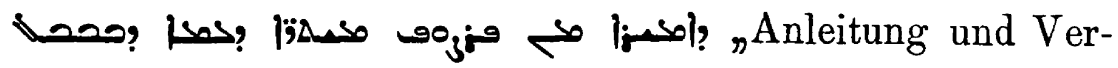
mahnung aller Menschen, gesprochen aus der Seele der

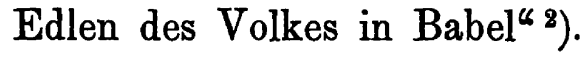

1) Lies por 9.

2) Hierber gehört endlich auch $\psi 10$ : 


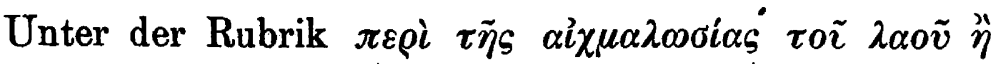

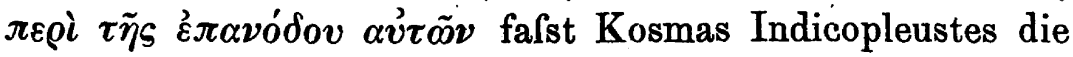
von Theodor historisch ausgelegten Psalmen zusammen; hierher gehören im syrischen Commentar bei weitem die meisten, nämlich alle bisher noch nicht besprochenen. Als Beweis, dafs der Syrer sich auch hier überall an Theodor angeschlossen hat, führe ich zunächst eine Anzahl solcher Ueberschriften an, welche aus den griechischen Fragmenten controllirt werden können. Auch hier bewährt sich die vorhin gemachte Bemerkung, dafs der Verfasser unseres Commentars nur die Stichworte aus Theodor excerpirt hat. Im Folgenden sind auch nun diese Stichworte aus den griechischen Fragmenten abgedruckt; für das Uebrige verweise ich auf Corderius.

33.

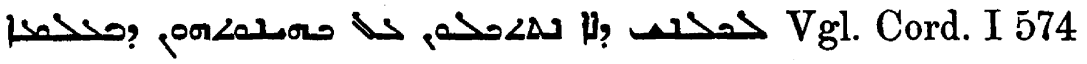

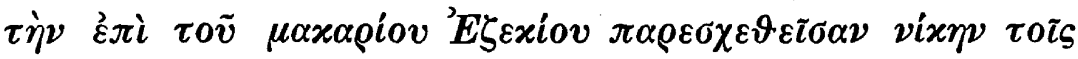

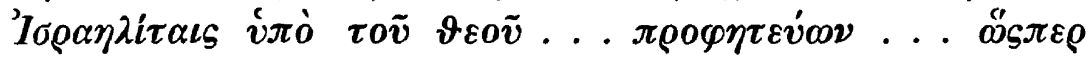

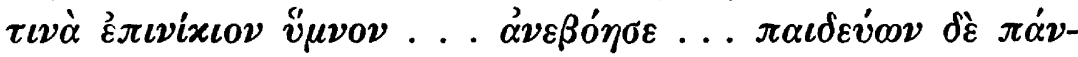

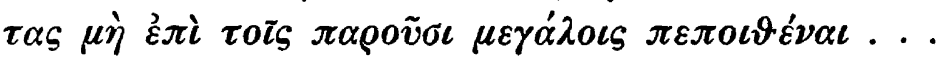

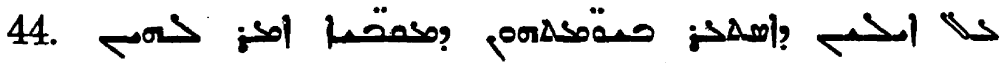

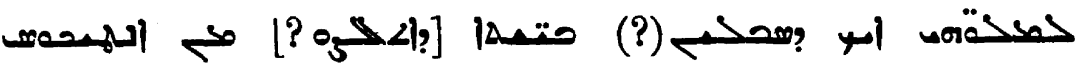
وبهصe. Cord. II 530 xai

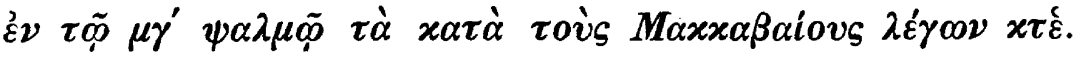

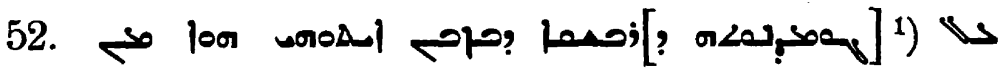

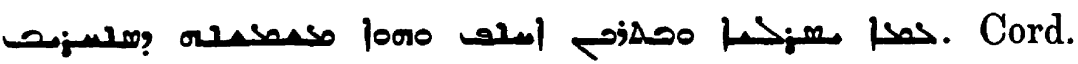

ordu2 פGegen die Reichen im Volk, welche die Armen bedrückten." Da aber Theodor der Abtheilung der LXX folgte, welche $\psi 9$ und 10 als einen einzigen zählen, so können diese Worte bei ihm jedenfalls nicht die Ueberschrift des Psalmes gewesen sein.

1) Die eingeklammerten Worte sind aus Bar Hebraeus entnommen. 


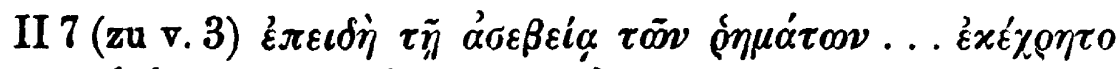

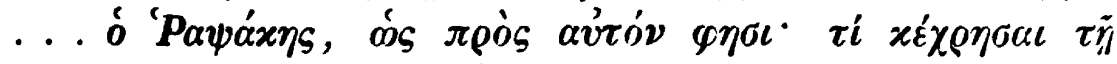

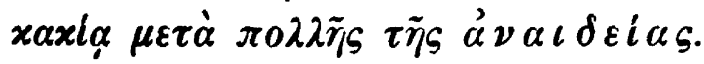

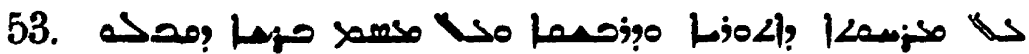

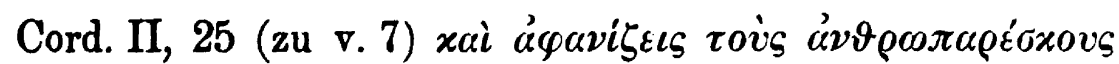

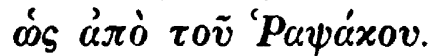

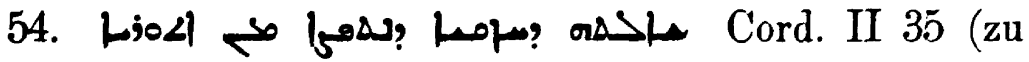

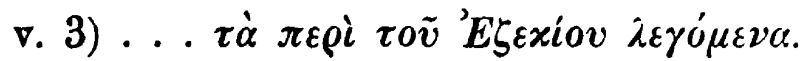

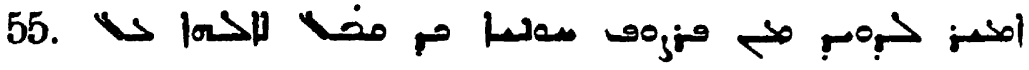

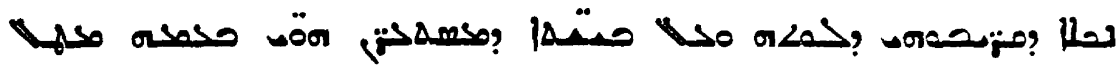

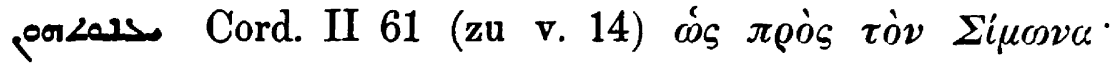

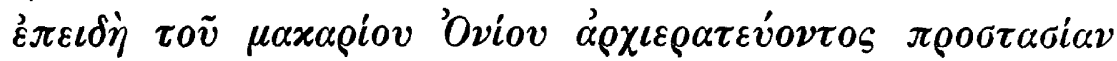
$\tau \iota \nu \dot{\alpha} \quad \xi \gamma \chi \varepsilon \chi \varepsilon \dot{\rho} \rho \iota \tau \sigma$.

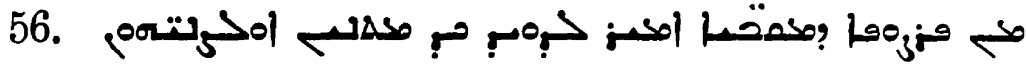

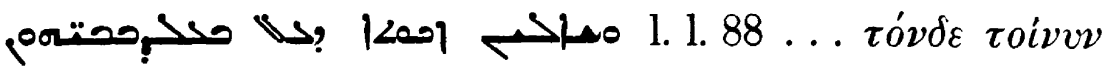

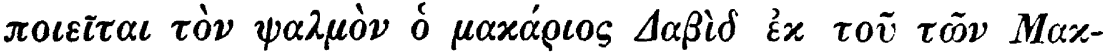

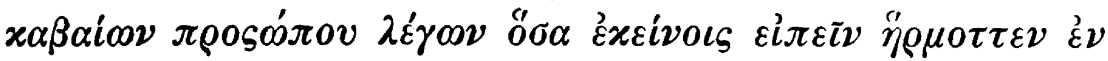
$\tau \alpha i \tilde{\varsigma} \sigma v \mu \varphi \circ \rho \alpha \tilde{\tau}$.

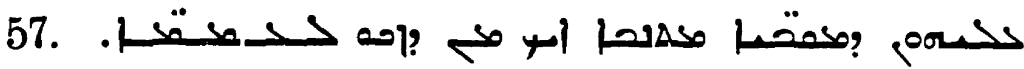
مor

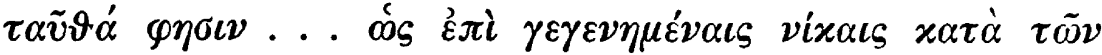

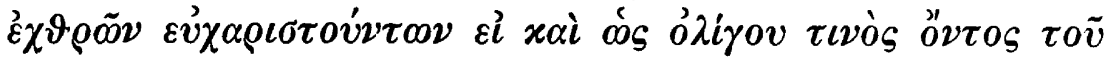

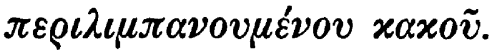

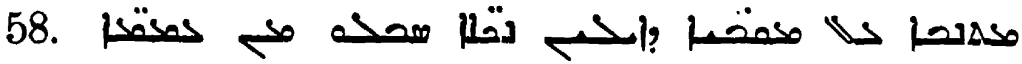

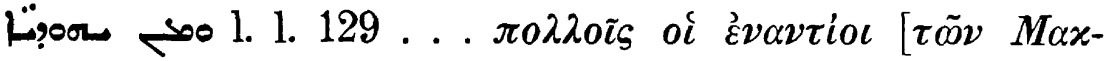

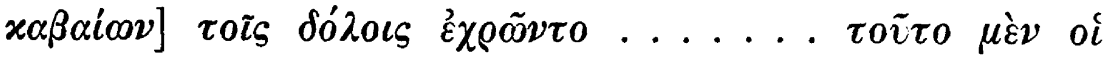

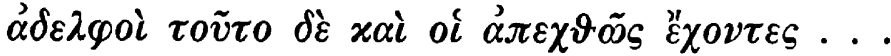

59. 152

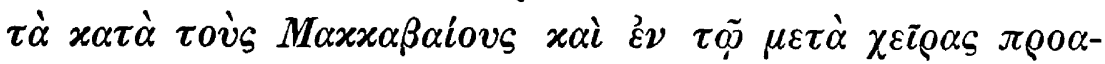

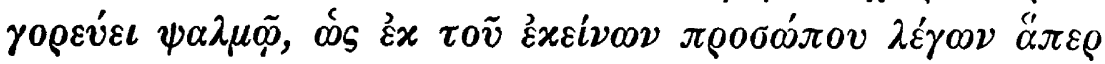




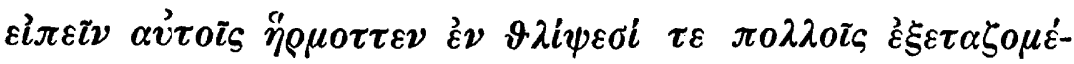

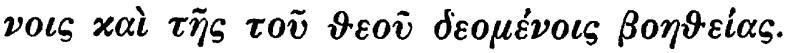

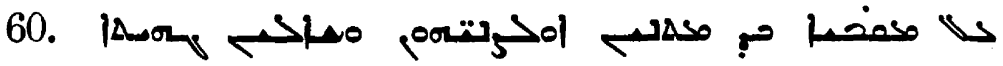

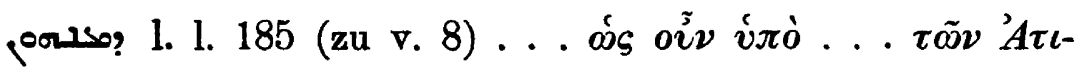

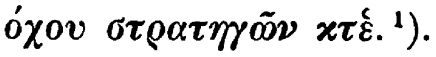

61. 1. 198

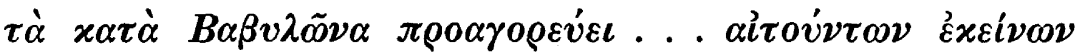
$\tau v \chi \varepsilon \tilde{i v} \tau \tilde{\eta} \varsigma$ $\tau o \tilde{v} \vartheta \varepsilon o \tilde{v} \beta o \eta \vartheta \varepsilon i \alpha \varsigma$.

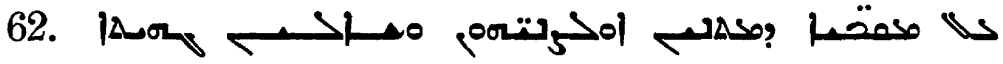

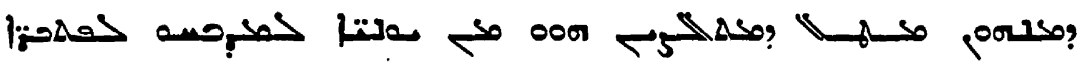
l. l. 219 (zu v. 19) œ́

65.

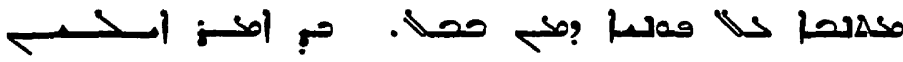

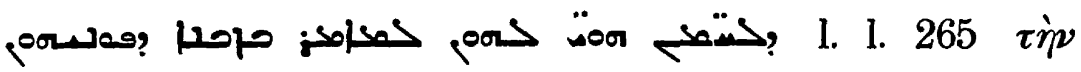

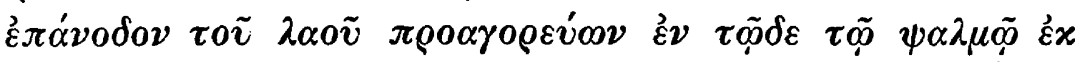

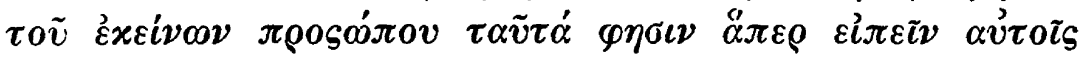

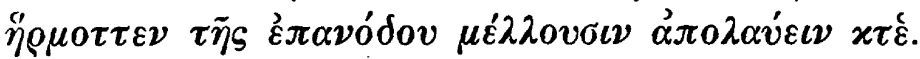

66.

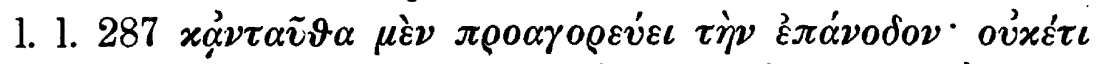

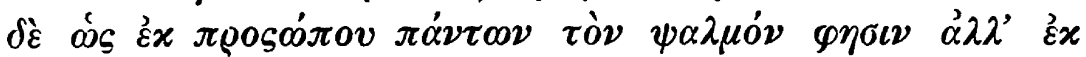

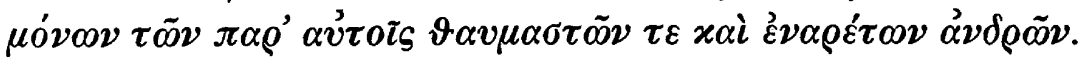

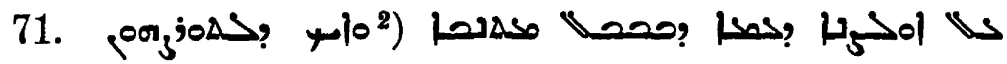

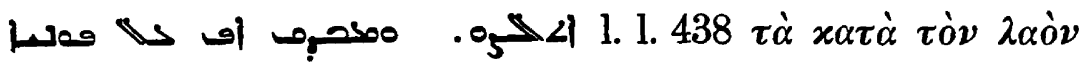

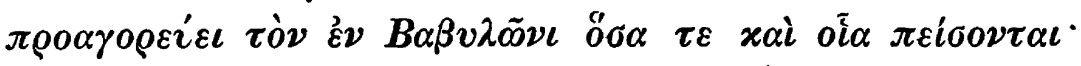

1) Da noch Kihn 1. 1. p. 87 die Ansicht vertritt, Theodor habe keine Kenntnifs des Hebräischen gehabt, so bemerke ich, dafs diese

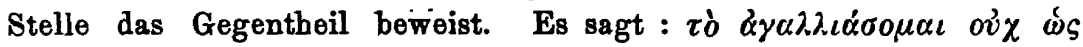

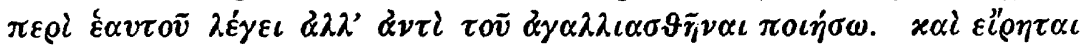

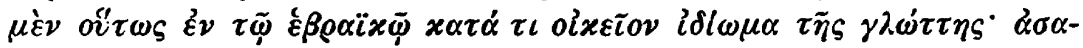

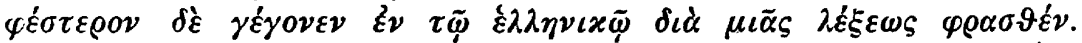
Theodor hielt also על על מלו nicht vorkommt.

2) Lies ?" (Bar Hebr.). 


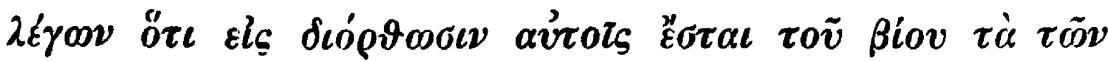

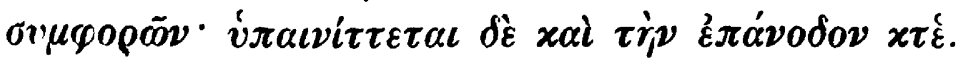

73. |ه

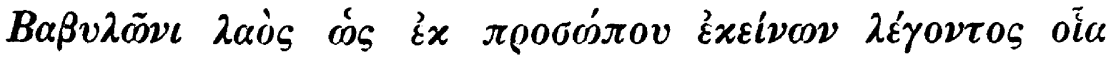

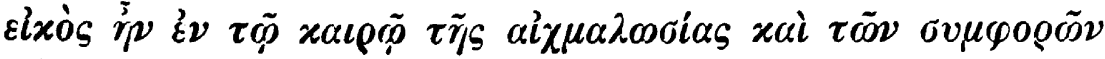

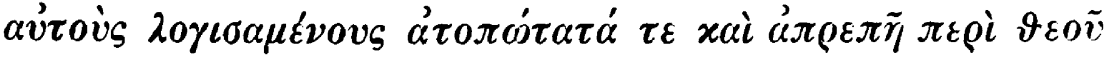

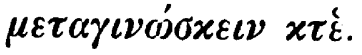

74.
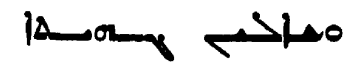

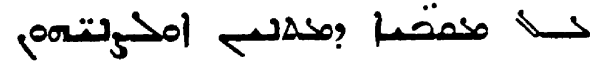

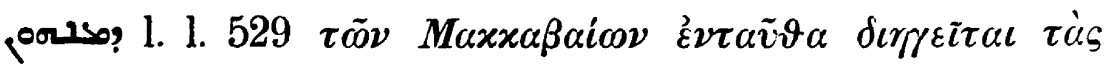

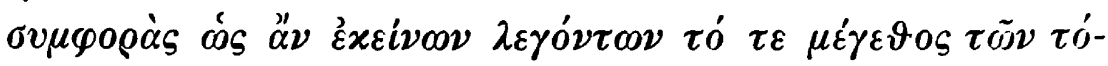

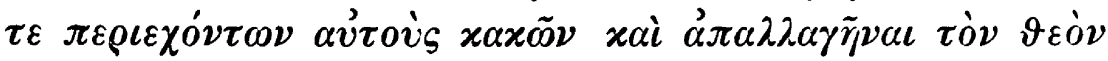

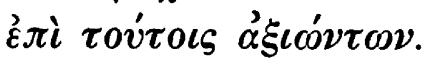

75.

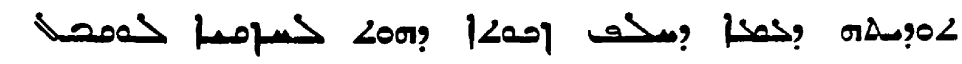

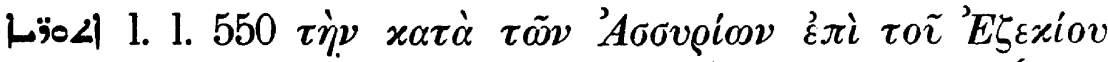

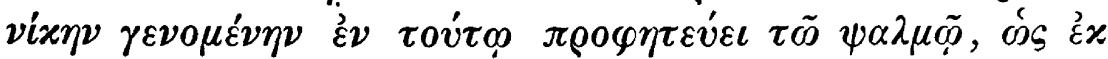

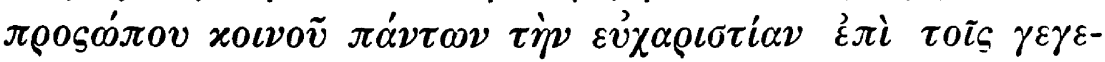

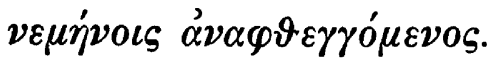

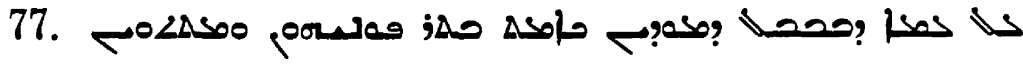

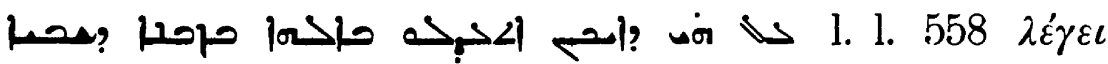

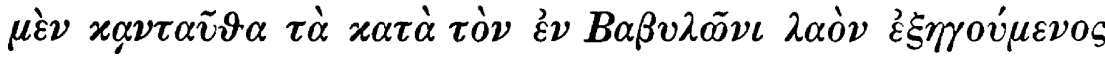

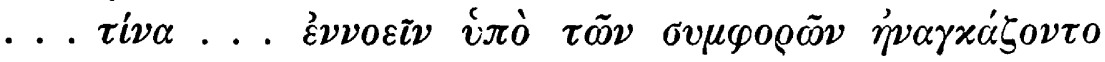

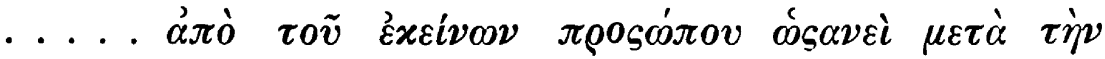

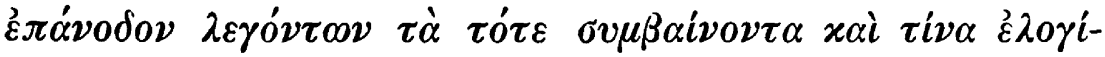
$\sigma \alpha \nu \tau o$.

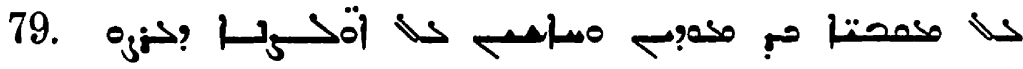

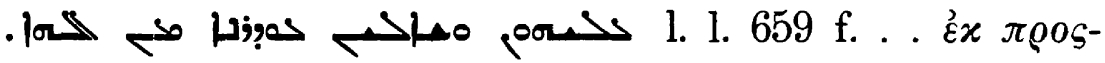

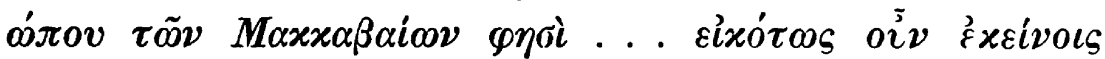

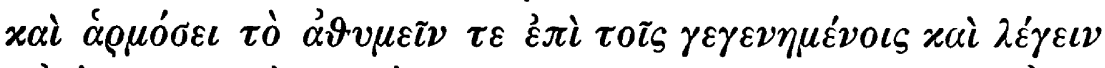

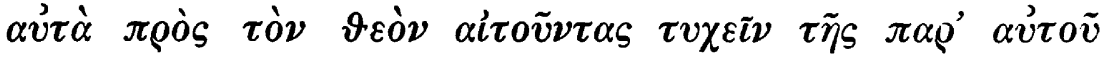
$\beta о \eta \vartheta \varepsilon i \alpha s . .$.

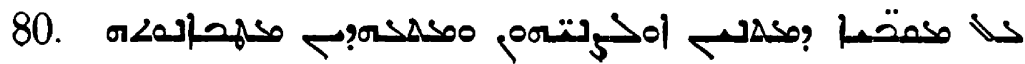




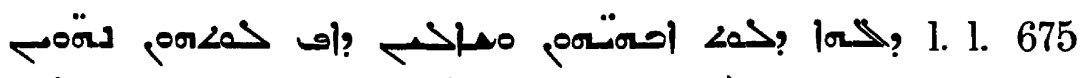

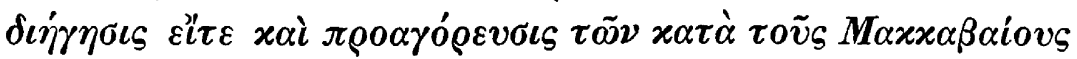

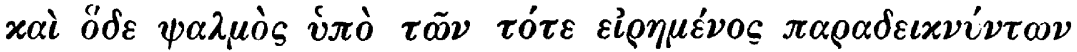

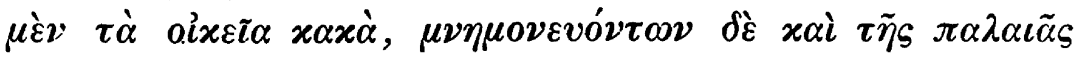

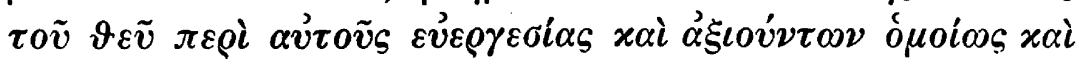

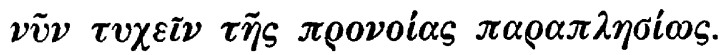

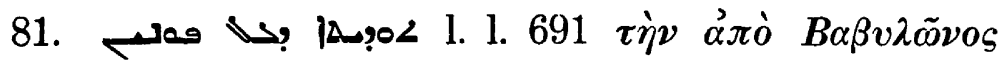

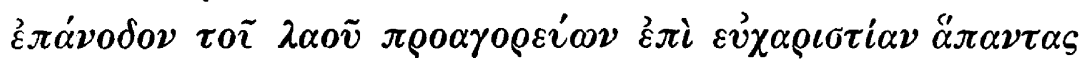

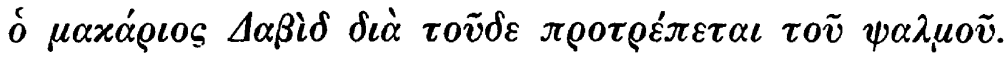

Hiermit sind die Stellen erschöpft, für welche sich aus den Fragmenten griechische Parallelen beibringen lassen. Unter allen diesen Beispielen fand sich kein einzigcs, in welchem der Syrer sachlich von der Auffassung Theodors abgewichen wäre. $\mathrm{Er}$ verkürzt allerdings seine Vorlage fast regelmäfsig mehr oder weniger, aber inhaltlich giebt er sie ausnahmslos wieder. Da nun unser Epitomator sich an allen Stellen, in denen er durch die griechischen Fragmente controllirt werden kann, als treuer Anhänger des Antiocheners bewährt, so wird man ihn auch in den Ueberschriften, für welche solche Controlle nicht möglich ist, als zuverlässige Quelle für Theodors Auffassung ansehen dürfen ${ }^{\mathbf{1}}$ ).

Theodors historische Deutungen sind interessant genug, um die Veröffentlichung der sämmtlichen im Vorhergehenden noch nicht mitgetheilten Inhaltsangaben aus dem syrischen Commentar zu rechtfertigen. Ich werde aber, um die Druckkosten zu vermindern, von jetzt an nur die deutsche Uebersetzung geben. Da, wie schon bemerkt, Bar Hebraeus sich die theodorischen Inhaltsangaben des syrischen Epitomators gröfstentheils buchstäblich angeeignet

1) Hiermit ist also auch für die oben unter den Rubriken $\pi \varepsilon \rho l$

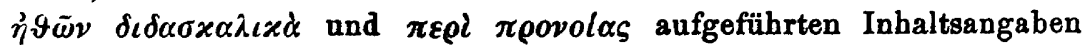
erwiesen, dafs dieselben sachlich auf Theodor zurückgehen. 
hat, so kann ich für den syrischen Text auf de Lagarde's Ausgabe verweisen. Wo es nöthig scheint wird auf die Differenzen der beiden syrischen Texte aufmerksam gemacht werden.

Auf David und seine Zeit werden folgende neunzehn Psalmen bezogen. 3. „Auf sich selbst dichtete David diesen Psalm in der Zeit, da er von seinem Sohne Absalom verfolgt wurde." 6. (s. o.) 7. „Gesprochen von David, als er hörte, dafs Achitophel sich erhängt hatte. ${ }^{\star}$ 9. „Dank des Volkes ') für den Sieg, welchen Gott ihnen über die umwohnenden Völker verliehen hatte.“ 11. „Auf sich selbst dichtete David diesen Psalm in der Zeit da er von Saul verfolgt wurde und seine Leute ihm riethen, vor ihm zu fliehen." 13. „Gebet Davids wegen seiner Sünde gegen Batseba." 16. (s. o.) ${ }^{y}$ ). 17. „Gebet David's aus der Zeit $\mathrm{da}$ er von Saul verfolgt wurde ${ }^{(3)}$ ). 18. „Dankgebet Davids für alles Gute, das Gott gethan hatte." 22. (s. o.). 36. „Gesprochen von David auf sich selbst als er von Saul verfolgt wurde." 38. „Gesprochen von David auf sich selbst wegen seiner Sünde gegen Batseba als er von Absalom verfolgt wurde und seine Sünde bekannte." 39. „Gesprochen von David auf sich selbst zu der Zeit, da er von Saul verfolgt wurde. Der Psalm mahnt uns aber, alle Bedrängnisse ohne Murren zu ertragen." 64. „Geprochen von David auf sich selbst, als er von Saul verfolgt wurde." 68. (s. o.). 70. „Von David gesprochen auf sich selbst als er von Absalom verfolgt wurde." 72. (s. o.). 120. (Pesch. 119) „Gesprochen [von David] in der Zeit als er

1) Bar Hebr. „Dank David's für den Sieg des Volkes und die Niederlage der umwohnenden Völker. “ Die Beziehung auf die davidische Zeit wird bestätigt durch Cord. I 272.

$\left.{ }^{2}\right)$ Die im syrischen Text nicht ausdrücklich ausgesprochene Beziehung auf die davidische Zeit ergiebt sich aus Cord. I 272.

3) Die Zeitbestimmung fand Bar Hebraeus nur in einigen Handschriften. 
von Saul verfolgt wurde und gezwungen war unter Fremden zu wohnen." 140. (139) „Gebet Davids um Rettung vor Saul und vor den Ohrenbläsern und Hinterlistigen ${ }^{1}$ ), die bei ihm waren."

Auf die assyrische Zeit sind die folgenden vier und zwanzig Psalmen bezogen.

14. „Auf die Gottlosigkeit und Frechheit des Sanherib und des Rabsake und von der Strafe, die sie empfingen." 15. „Gesprochen im Namen des Volkes, nachdem sie aus den Kriegen mit den Assyrern gerettet waren ${ }^{2}$ ). 20. „Gebet des Volkes für Hiskia, dafs er von den Assyrern gerettet werde. “ 21. „Gesprochen im Namen Hiskia's, nach dem Tode des Assyrers. “ 27. „Dank im Namen Hiskia's, nachdem er von den Assyrern befreit war" ${ }^{3}$ ). 28. „Gesprochen [im Namen Hiskia's] ${ }^{4}$ ) als er von den Assyrern befreit war und von einer Krankheit ergriffen wurde. ${ }^{4}$ 29. „Wie es dem Hiskia zieme, nach dem Tode der Assyrer das Volk aufzufordern, Opfer darzubringen. ${ }^{*}$ 30. „Gesprochen im Namen Hiskia's als er seine Hoffart bereute; dazu Dank für seine Genesung und die Zurechtweisung seiner Sünde." 32. „Gesprochen auf Hiskia als er von seiner Krankheit befreit war; der Psalm mahnt in seinem Namen alle Menschen, auch wenn sie tugendhaft sind, nicht auf ihre Tugend zu vertrauen." 33. (s. o.). 34. „Dank im Namen Hiskia's und seines Volkes für das, was ihnen widerfahren war. Der Psalm mahnt alle Menschen, auf Gottes Hülfe zu harren.“ 41. „Gesprochen auf Hiskia als

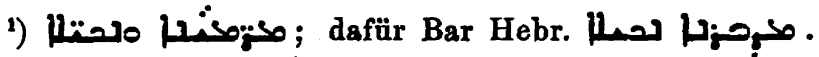

2) Bar Hebr. vollständiger : ${ }_{n}$ Lehrt das Volk, sich nicht darauf zu verlassen, dafs sie im Kriege mit den Assyrern errettet waren, sondern eifrig Sorge zu tragen, dafs sie das Gesetz beobachteten."

s) Die Ueberschriften zu 21 und 27 sind bei Bar Hebr. vertauscht und weichen aufserdem etwas vom vorliegenden Text al.

4) Bar Hebr. : „Gesprochen von David im Namen Hiskias als seine Freunde treulos gegen ihn waren und sich über ihn freuten zur Zeit seiner Krankheit. ${ }^{4}$ 
er todtkrank wurde und was ihm widerfuhr von Seiten seiner Freunde als er krank war." 46. „Auf Ahas und Hiskia, welche von den Damascenern und von Ephraim errettet waren und dankten, dals sie von ihnen befreit waren. ${ }^{*}$ 48. „Erzählt von Hiskia, sofern dieser jedermann aufforderte Gott zu danken für den Sieg, der ihm über die Assyrer verliehen war. ${ }^{\star}$ 52. 53. 54. 75. (s. o.). 76. „Ebenfalls auf Hiskia; Dank des Volkes für den Sieg des Hiskia über die Assyrer.“ 86. „Auf Hiskia als er wegen der Assyrer betete. ${ }^{“}$ 87. „Auf die Errettung Jerusalem's vor den Assyrern.“ 91. „Auf Grund des Sieges, welcher dem Volke über die Assyrer wegen der Tugend des Hiskia zu Theil geworden war, vermahnt David alle Menschen und verspricht, dals ihnen dergleichen zu Theil werden soll, wenn sie auf ihre Tugend Bedacht nehmen." 92. „Dank des Volkes für Hiskia wegen seines Sieges über die Assyrer." 117 (Pesch. 116) „Im Namen Hiskias mahnt er alle Menschen Gott zu danken."

Aufser diesen in den Ueberschriften auf die assyrische Zeit bezogenen Psalmen findet sich 116 (Pesch. 115) v. 10 die Bemerkung : „Bis hierher weissagt er auf das Volk in Babel; von hier an und weiter auf Hiskia als er krank geworden war, weil er in seinem Sinne über den Tod der Assyrer hochmüthig geworden war, indem er von sich selbst Grofses dachte." Dies ist offenbar die Ueberschrift, welche Theodor dem nach dem Septuagintatext hier beginnenden 115. Psalm gab.

Auf die chaldäische Periode und die Rückkehr aus der Gefangenschaft sind folgende sechs und sechszig Psalmen gedeutet.

5. „Weissagung auf das Volk in Babel, das Gott um Rückkehr bittet.“ 23. „Auf die Erquickung und Wonne, die ihnen beim Auszug aus Babel zu Theil wurde." 24. „Vermahnung des Volks in Babel, die Hoffnung auf Rückkehr nicht aufzugeben." 25. „Gesprochen auf das Volk 
in Babel und dessen Gebet um Rückkehr." 26. „Gesprochen im Namen der Edlen in der Verbannung, welche um Erlösung baten. " 31. „Gebet des Volks in Babel um Rückkehr. ${ }^{*}$ 40. „Weissagung auf das Volk in Babel, welches seine Bedrängnisse erzählt." 42. „Gesprochen auf das Volk in Babel, sofern es sich nach der Rückkehr sehnte und über seine Entfernung vom Tempel Gottes bekümmert war." 43. „Weissagung auf das Volk, sofern es bat, dafs ihnen Recht gegen die Babylonier werden möge." 51 . „Gesprochen auf das Volk in Babel, welches seine Sünden bekennt und um Vergebung und Aufhören seiner Verbannung bittet $\left.{ }^{* 1}\right)$. 61. „Weissagung auf das Volk in Babel, welches um Hülfe bittet." 63. „Auf die Edlen des Volks in Babel, welche sich nach der Rückkehr sehnten. ${ }^{*}$ 65. 66. (s. o.). 67. „Weissagt die Rückkehr des Volks und lehrt die Priester, dafs es ihnen dann ziemt, Gott Loblieder zu singen ${ }^{2}$ ), wenn sie in ihre Heimath zurückgekehrt sind.“ 71. 73. 77. 81. (s. o.). 84. „Auf die Rückkehr des Volkes aus Babel, sofern es bereits ausgezogen, aber noch nicht in Jerusalem angekommen war, und [staunend] ${ }^{3}$ ) der Vorzeit gedachte. ${ }^{\star}$ 85. „Als das Volk von Cyrus die Erlaubnifs erhalten hatte in die Heimat zurückzukehren, und Gott bat, ihre Hoffnung zu erfüllen." 88. „Auf das Volk in Babel, welches seine Bedrängnisse erzählt und um Erlösung von denselben bittet. ${ }^{*}$ 89. (s. o.). 90. „Im Namen des Volks in Babel, welches bittet, dals seine Leiden aufhören möchten. ${ }^{*}$ 93. „Weist auf die Gröl'se der göttlichen Hülfe bei der Rückkehr seines Volks hin.“ 94. „Auf das Volk in Babel, welches die in der Zeit

1) จ. 6 "gegen dich allein habe ich gesündigt" wird erklärt aus dem Gegensatz : „und nicht gegen die Babylonier."

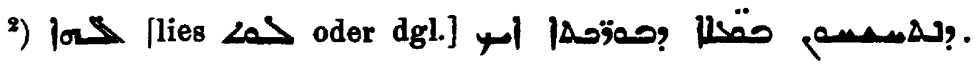

s) 
der Verbannung ertragenen Leiden erzählt.“ 95̃. „Weissagt auf das Volk in Babel und mahnt und ruft sie auf Grund des Geschehenen zum Preise Gottes.“ 96. „Dank für die Rückkehr aus Babel.“ 97. „Weissagt die Rückkehr des Volks, dichtet ein Siegeslied ") und beschreibt ${ }^{2}$ ) die Veranstaltung Gottes.“ 98. „Auf die Rückkehr, und fordert jedermann zum Danke auf. ${ }^{*}$ 99. „Weist auf die Rückkehr hin und mahnt sie auf Grund dessen, was früher geschehen zum Lobe.“ 100. „Mahnt das Volk als die aus der Gefangenschaft zurückgekehrten in den Tempel zu gehen und Gott zu danken." 101. „Gesprochen im Namen der Edlen des Volkes in Babel zur Zeit ihrer Leiden." 102. „Erzählt von den Leiden des Volkes in Babel und von ihrer Rückkehr." 103. "Mahnt das Volk Gott für ihre Rückkehr zu danken." 106. „Auf das Volk in Babel, welches bekennt, dals es gesündigt hat, und Gott um Barmherzigkeit bittet, dals er sich ihrer erbarme." 107. ${ }_{n}$ Auf die Rückkehr von Babel, indem er das Volk antreibt Gott zu danken, der sie aus ihren verschiedenen Uebeln errettete. ${ }^{*}$ 116. (Pesch. 115) ${ }^{3}$ ). "Auf das Volk in Babel, welches Gott für seine Rückkehr dankt." 118. (s. o.). 121. „Auf die Rückkehr und auf die Vermahnung an das Volk und an Jedermann. “ 122. "Gesprochen im Namen der Edlen, welche von Babel zurückkehrten ${ }^{4}$ ), sofern sie sich über ihre Rückkehr freuten.“ 123. „Auf das Volk in Babel, sofern es im Glauben ${ }^{5}$ ) Errettung von denen

1) Im Text ist ausgefallen , קك-i s. Bar Hebr.

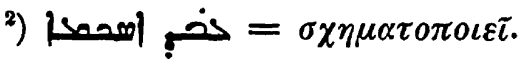

s) 114 und 115 sind wie bemerkt in der Peschita zu Einem Psalm zusammengezogen, daher hat auch 115 (nach hebräischer Zählung) keine Ueberschrift.

4) Bar Hebr. : ${ }_{n}$ welche in ihrer Jugend fortgeführt waren und im Alter zurückkehrten."

5) Bar Hebr. fügt hinzu : „ohne zu zweifeln." 
erbat, welche es fortgeführt hatten.“ 124. „Auf das Volk in Babel, sofern es zurückgekehrt war und der Leiden der Verbannung und der Errettung gedachte." 125. „Auf den Sieg des Volks nach der Rückkehr ${ }^{1}$ ). 126. „Auf das Volk, welches fortgeführt war und die Rückkehr erbat und versprach, was es thun werde, wenn es zurückkehren würde." 127. „Gesprochen im Namen des Volks nach seiner Rückkehr, als seine Feinde es am Bau des Tempels hinderten." 128. „Vermahnt diejenigen, welche von Babel zurückgekehrt waren, auf Tugend bedacht zu sein, um sich der Gnade Gottes zu erfreuen.“ 129. „Diejenigen, welche aus Babel zurückgekehrt waren, mahnt er, Gott für seine früheren Gnadengaben zu danken. * 130. „Gesprochen im Namen der Edlen des Volks in Babel.“ 131. „Gesprochen im Namen der Edlen des Volks" ${ }^{2}$ ). 132. „Weissagt auf das Volk in Babel, sofern es Gott erinnert*3). 133. „Deutet an, dafs nach der Rückkehr des Volks aus Babel Israel [und Juda] ${ }^{4}$ ) sofort zusammen wohnen werden. ${ }^{*}$ 134. „Sofern das Volk von Babel zurückgekehrt ${ }^{5}$ ) und der Tempel gebaut ist und man Gott dankt $\left.t^{46}\right)$. 135. [n Mahnt] ${ }^{7}$ ) das von Babel zurückgekehrte Volk, Gott zu danken." 136. „Sofern das Volk von Babel zurückgekehrt ist, lehrt er sie Grott zu danken für alle seine ihnen erwiesenen

1) Bar Hebr. fährt fort „nachdem sie Gog, der über sie gekommen war, überwältigt hatten."

2) Bar Hebr. fährt fort : ${ }_{n}$ in Babel, indem er ihren in der Freimüthigkeit ( $\pi \alpha \varrho \varrho \varrho \eta \sigma l \alpha$ ) ihrer Worte sich offenbarenden Charakter kund thut. Er palst aber auf Hananja und Daniel."

3) Bar Hebr. fährt fort.: nan Davids Liebe gegen ihn, und ihn wegen seiner Verheifsungen an ihn um Erbarmen bittet."

4) Ergänzung nach Bar Hebr.

5) Ms. Olas ; lies a (Bar H.).

6) Bar Hebr. : "Sofern ... gebaut ist, treibt or sie an, Gott ihrem Befreier Preis darzubringen."

7) Ergänzung aus Bar Hebr.

Zeitschrift f. d. alttest. Wiss. Jahrgang 5. 1885. 
Wohlthaten." 137. „Auf das Volk in Babel, welches seine Leiden erzählt." 138. „Auf das von Babel zurückgekehrte [Volk], welches Gott für seine Errettung dankt. “ 139. „Im Namen der Edlen des Volks in Babel ${ }^{1}$ ), welche flehten, die Rückkehr zu erlangen, spricht er weiter über die unendliche Gröfse und Weisheit Gottes." 141. „Auf das Volk in Babel gesprochen, sofern dasselbe erzählt, dafs es in Folge der Verbannung gute und rechte Sittlichkeit (التا) gewunnen habe." 142. „Gebet des Volks in Babel, welches Gott um Aufhören seiner Leiden ${ }^{2}$ ) anfleht.“ 143. [„Auf] das Volk in Babel, welches im Gebet zu Gott fleht.“ 145. „Auf das Volk in Babel, welches Gott für die Errettung aus den Leiden dankt." 146. „Gesprochen im Namen des Volks, welches von Babel zurückgekehrt war." 147. [„Weissagt auf das Volk in Babel und dankt in dessen Namen für das Gute, welches Gott ihnen seit der Rückkehr erwiesen ${ }^{*} .^{3}{ }^{3}$ ) 149. „Mahnt das Volk nach ihrer Rückkehr aus Babel und dem Siege über ihre Feinde [Gott ohne Aufhören zu loben“.] ${ }^{4}$ ) 150. „Vermahnung an das Volk [in Babel] ${ }^{4}$ ), Gott, seinen Schöpfer, allezeit zu loben. ${ }^{*}$ Auf die makkabäische Zeit sind die folgenden siebzehn Psalmen bezogen.

44. (s. o.). 47. „Auf die Makkabäer und ihren Sieg in den Kriegen." 55. 56. 57. 58. 59. 60. 62. 69. 74. 79. 80. (s. o.). 83. „Gesprochen im Namen der Makkabäer, nachdem sie von Antiochus errettet waren und sich die

1) Ms פوصحس (Bar Hebr.).

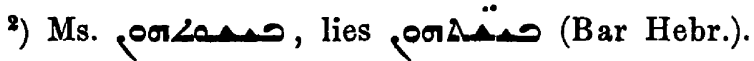

3) Im Ms. fehlt die Ueberschrift; die Uebersetzung ist aus Bar Hebr. entnommen. 147, 12 (hebr.) beginnt bei Pesch. und LXX ein neuer Psalm. Ueberschrift "Im Namen derer, welche aus Babel zurückgekehrt waren, sofern sie Gott loben für das was ihnen widerfahren."

4) Die eingeklammerten Worte aus Bar Hebr. 
umwohnenden Völker aus Neid gegen sie sammelten, um sie zu vernichten.“ 108. „Dank der Makkabäer für ihnen Sieg.“ 109. „Auf die Makkabäer, welche erzählen, wie viel Leiden sie ertrugen von den Fremden ${ }^{* 1}$ ). 144 (Pesch. 143). „Dank der Makkabäer für ihren Sieg, den sie über ihre Feinde davongetragen hatten."

Auf das Volk ohne weitere Zeitbestimmung ist bezogen 111 „Dank des Volks für alle Wohlthaten, welche es von Gott empfangen hatte."

Endlich ist ein Psalm auf Jeremia gedeutet. 35. „Im Namen Jeremias von David gesprochen, indem er die Leiden erzählt, welche er von seinen Volksgenossen zu ertragen hatte." v. 11 wird hier auf Jerem. 37, 13 bezogen; v. 12 auf Jerem. 38, 4.

Es bleibt noch die Frage zu beantworten, wann der Syrer lebte, der uns die spärlichen Excerpte aus Theodors Psalmencommentar erhalten hat. Für diesen Zweck ist es zunächst nothwendig festzustellen, in welchem Verhältnifs die Scholien des Bar Hebraeus zu unserem Commentar stehen.

De Lagarde's Vermuthung, welche er in der Vorrede zu seiner Ausgabe der Scholien ausspricht, dafs zu den von Bar Hebraeus für sein Werk verwandten Schriftstellern gehört hätten Theodori Mopsuhesteni epitomatores nescio quos wird durch unsern Epitomator glänzend bestätigt; der jakobitische Primas hat sich die Excerpte aus dem Commentar des nestorianischen „Exegeten " grölstentheils angeeignet und zur Grundlage seines eigenen Buches gemacht.

Die Ueberschriften der Psalmen bei $\mathrm{BH}$ und $\mathrm{N}^{2}$ )

1) Bar Hebr. fahrt fort : „und von ihren Volksgenossen, und zu Gott flehen, dafs er Strafe auf sie herabsenden möge."

9) $\mathbf{B H}=$ Bar Hebraeus, $\mathbf{N}=$ der Epitomator Theodors. 
stimmen in den meisten Fällen buchstäblich überein; geringe Abweichungen bei einer weiteren ziemlich grofsen Anzahl sind als verschiedene Lesarten zu betrachten. Wenn $\mathrm{BH}$ hin und wieder vollständiger ist als $\mathrm{N}$ (s. z. B. 15. 122. 131-135), so erklärt sich dies daraus, dafs ihm ein besserer Text vorlag als unser im Jahre 1882 geschriebenes Manuscript ihn bieten kann. BH weist aber auch ebenso oft $\mathrm{N}$ gegenüber eine verkürzte Textgestalt auf, z. B. 32. 42. 46. 48. 50. 65. 76. Wenn dies nicht auch aus Corruption der Handschriften zu erklären ist, so wird man den Grund in dem Streben nach Kürze zu suchen haben, welcher die Scholien des BH kennzeichnet.

BH hat sich aber nicht allein die Ueberschriften aus $\mathrm{N}$ angeeignet, sondern ebenso einen grofsen Theil der Erläuterungen selbst. Ein Vergleich zwischen den von mir aus $\mathrm{N}$ gegebenen Proben mit dem gedruckten Text der Scholien beweist dies schlagend, s. besonders die messianischen Psalmen, ferner Stellen wie 12, 9 u. a. Bei einer vollständigen Veröffentlichung von $\mathrm{N}$ würde sich BH's Abhängigkeit von ihm Zeile für Zeile nachweisen lassen. Auch hier gilt nun das bereits von den Ueberschriften Bemerkte, daIs nämlich $\mathrm{BH}$ bald vollständiger ist und einen besseren Text liefert als $\mathrm{N}$, ihn bald aber auch noch mehr verkürzt, so dafs beide sich gegenseitig ergänzen ${ }^{\mathbf{1}}$ ). Im Grofsen und Ganzen aber sind die mit $\mathrm{N}$ bezeichneten Excerpte aus Theodor von $\mathrm{BH}$ in seine Scholien aufgenommen und zur Grundlage derselben gemacht, nur dals der letztere nicht eine fortlaufende Paraphrase des ganzen Psalmentextes giebt wie $\mathrm{N}$, sondern die einzelnen $z u$ erläuternden Worte herausgreift. Es ist kaum nöthig her-

1) Hin und wieder hat aber der Jakobit den Nestorianer auch corrigirt, so wenn er $\psi 16$ ausdrücklich auf die Auferstehung Christi bezieht. Vgl. dazu Bar Hebr. bei Kihn 1. 1. 60 : Si enim ... Theodori expositiones ab initio examen subiissent, non ea zizania exorta fuissent, quae etiam nunc ab ecclesiae campo purgari nequiverunt. 
vorzuheben, wie sehr in Folge dieses Nachweises die von de Lagarde herausgegebenen Scholien an Werth gewinnen. Die weiteren Quellen dieser Scholien nachzuweisen ist nicht die Aufgabe der vorliegenden Untersuchung.

Als terminus ante quem für die Abfassung von $\mathrm{N}$ ist 1286 p. Chr. († Bar Hebraeus) gefunden; weiter wird sich nicht viel sagen lassen. Bei $\mathrm{N}$ selbst findet sich keine Spur einer Nachricht davon, wer der Epitomator gewesen ist. $\mathrm{Ob}$ die Ueberschrift unserer Handschrift, in welcher Theodor selbst als directer Verfasser genannt wird, ihren Ursprung erst dem Diakonen Franciscus verdankt, oder ob dieser sie schon in seiner Vorlage fand, mufs dahingestellt bleiben. Unter den syrischen Nestorianern hat es eine recht grofse Anzahl von Erklärern des alten Testaments gegeben, unter denen man ziemlich beliebig wählen kann. Narses Garbânâ ( $†$ 496), der wegen seines engen Anschlusses an Theodor ${ }^{1}$ ) bei den Nestorianern als Exeget aufserordentlich hochgeschätzt wurde, ist es nicht gewesen, da er grade die Psalmen nicht ausgelegt hat ${ }^{2}$ ).

Der unbekannte Verfasser verfolgte in erster Linie das Ziel, Theodor's Commentar in möglichst knapper Form zu excerpiren; aufserdem gab er originalsyrische Erk]ärungen unverständlich gewordener Worte des Psalmentextes selbst und benutzte vereinzelt auch noch andere Quellen, die zur Zeit nicht nachweisbar sind.

Wir wollen ihm dafür dankbar sein, dafs in Folge seiner Arbeit ein Schimmer von dem leuchtenden Gestirn in Antiochien bis zu uns hindurchgedrungen ist.

$\mathrm{Kiel}$, den 20. October 1884.

1) Amru bei Assem. B. O. III I 64 كارن بفسّر ... . . . nEr legte die Schriften aus und wich dabei nicht von den Spuren Theodor's ab."

2) B. 0. 1. 1. 65 . 